\title{
Natural ventilation potential for residential buildings in a densely built-up and highly polluted environment. A case study
}

Article

Accepted Version

Costanzo, V., Yao, R., Xu, T., Xiong, J., Zhang, Q. and Li, B. (2019) Natural ventilation potential for residential buildings in a densely built-up and highly polluted environment. A case study. Renewable Energy, 138. pp. 340-353. ISSN 0960-1481 doi: https://doi.org/10.1016/j.renene.2019.01.111 Available at https://centaur.reading.ac.uk/83630/

It is advisable to refer to the publisher's version if you intend to cite from the work. See Guidance on citing.

To link to this article DOI: http://dx.doi.org/10.1016/j.renene.2019.01.111

Publisher: Elsevier

All outputs in CentAUR are protected by Intellectual Property Rights law, including copyright law. Copyright and IPR is retained by the creators or other copyright holders. Terms and conditions for use of this material are defined in the End User Agreement.

www.reading.ac.uk/centaur 
Central Archive at the University of Reading

Reading's research outputs online 
Natural ventilation potential for residential buildings in a densely built-up and highly polluted environment. A case study

Vincenzo Costanzo ${ }^{\text {a, }}{ }^{*}$, Runming Yao ${ }^{\text {a, b, }{ }^{* *} \text {, Tiantian Xu }}{ }^{\text {b }}$, Jie Xiong ${ }^{\text {a, b }}$, Qiulei Zhang ${ }^{\text {, }}$ Baizhan Li ${ }^{\text {b }}$

a School of the Built Environment, University of Reading, Reading RG6 6DF, UK Chine

\section{Abstract}

The application of Natural Ventilation (NV) as a measure to improve comfort conditions in transition and summer periods has been a topic of research on the spotlight for years. However, there is a lack of knowledge about how the combined effect of a dense urban layout with high pollutant concentrations may affect its potential. This paper addresses this gap by running detailed thermal simulations for a typical apartment flat located in the Yuzhong district of Chongqing city (China) using a holistic approach that makes use of: i) wind pressure coefficients on building facades from urban-scale CFD simulations, ii) hourly measured values of PM2.5 concentrations and weather variables and iii) indoor environment measurements for validation purposes. Scenario analysis revealed the average amount of air change rates achievable in a year varies from 8 to $15 \mathrm{ACH}$ according to the windows orientation. These figures drop down to around $2 \mathrm{ACH}$ when taking into account reduced windows opening time when outdoor PM2.5 concentrations are too high. The resulting natural ventilation potential of the case study decreases from 4234 hours when outdoor pollution is neglected to 2707 and 529 hours when considering the exposure thresholds set by the Chinese government and the WHO respectively.

Keywords: natural ventilation, PM2.5, IAQ, coefficient of pressure, thermal comfort, experimental measurements

\section{Introduction}

The tremendous increase rate in buildings' energy consumption of over $45 \%$ recorded in the last two decades in China [1] can be explained by the thrilling economy growth and urbanization rates 
experienced in this country [2]. The Chinese government is concerned about the environmental issues connected with these increasing trends, and set a series of measures aimed at reducing carbon emissions per GDP unit of $60-65 \%$ by 2030 on a 2005 baseline [3] while improving the energy efficiency in the building sector [4]. In parallel, great attention is paid to the improvement of people's living environments as far as health and productivity are concerned [5], thus posing great challenge in terms of balance with the achievement of the energy savings goal.

As reported by the Tsinghua 2016 Annual Report on China building energy efficiency [6], a proportion ranging from 30 to $60 \%$ of the energy consumed by houses is used to maintain comfortable indoor conditions, with variations due to different climates [7], HVAC systems [8] and occupants' long-term thermal adaptation [9-10].

Among the five climate zones defined for energy calculation purposes in ref. [7], the Hot Summer Cold Winter (HSCW) zone stands out for its unique characteristics. Most of its 550 million inhabitants, out of which more than a half live in cities, reside in flats where the average indoor temperatures range from 25 to $35^{\circ} \mathrm{C}$ in summer [11].

Natural ventilation is regarded as an effective measure of low energy building design by several authors $[1,12,13]$, and the benefits connected with the use of natural ventilation as a passive cooling technique during transition and summer periods in the HSCW zone have recently raised an increasing attention of researchers and scholars, especially in terms of cooling energy savings thanks to reduced HVAC usage. As examples, Nie et al. [14] used CFD analysis and Building Energy Simulation (BES) to analyze how different openings position and orientation affect ventilation rates and cooling energy consumption of an apartment flat in Changsha. The main finding was a dichotomy between the best building orientation for maximizing ventilation rates (the west one namely) and that for minimizing the annual energy consumption (the south orientation). This problem has been solved by the authors introducing a balancing point that guarantees both low energy consumption and an acceptable amount of air change rates for passive cooling purposes.

$\mathrm{Fu}$ et al. [15] employed BES for assessing the benefits of night ventilation strategies in a typical apartment flat located in five different cities (Hanzhong, Nanjing, Hanzhou, Changsha and Guillin namely) and built according to the German Passivhaus Standard criteria. Parametric studies have been carried out by Yao et al. [16] and Wang et al. [17] to find out the geometrical and thermal configurations that maximize the number of comfort hours in free-running conditions. The use of the adaptive thermal comfort theory to assess indoor conditions according to several simulation iterations, allowed identifying poor thermal performances of the existing residential stock built according to old construction standards, especially in summer when natural ventilation is not employed systematically. However, outdoor air pollution causes a problem to the application of natural ventilation; hence, an 
understanding of the pollutant concentration dynamics is essential to the application of natural ventilation to achieve thermal comfort and energy savings [18].

\subsection{Previous studies}

Due to the thrilling economic growth experienced in the last decades, China is facing serious environmental hazards and degrading air quality. It is reported that cities in east-central China, together with those located in the Plain of Ganges River in India, are ranked amongst the twenty most polluted cities in the world [19].

Among the different airborne pollutant sources, Particulate Matter with an aerodynamic diameter lower than $2.5 \mu \mathrm{m}$ (PM2.5) is of particular concern because the very small size allows easily reaching the pulmonary alveoli and thus causing serious respiratory and cardiovascular diseases [20-22].

Notwithstanding the relevance of the topic, just few papers attempted to comprehensively consider the effects of wind-induced airflow on the dispersion of pollutants inside the buildings, and how this would affect the natural ventilation potential of providing good thermal and indoor environmental quality conditions.

As shown in Table 1 and recently pointed out in a review paper from Toparlar et al. [23], some authors started investigating different scales of analysis at the same time by coupling CFD tools with BES software in order to have a comprehensive understanding of the mass transfer phenomena. Majority of these works considered either the single building scale or idealized urban geometries, as in [24-26] where regular and staggered layouts of buildings surround the study one, while real urban morphologies are less common [27-29].

Among the different papers reviewed and reported in Table 1, it is worth to briefly discuss some of them for the variety of approaches deployed and for highlighting the gaps that this paper aims to fill. As an example, Park et al. [30] carried out a field study of fifteen single-family apartments in three different sites located in the city of Seoul (South Korea) equipped with different ventilation systems (balanced, unbalanced and natural ventilation namely). For all ventilation types, indoor concentrations - expressed in terms of indoor to outdoor ratio - were find lower than outdoor ones because of deposition onto indoor surfaces and of an efficient filtration process in the case of mechanical ventilation. However, no reference is made to the surroundings, so that it is not possible to understand how the urban layout affects the results of the monitoring campaign.

Tong et al. [31] have employed a more detailed and fully coupled approach in a study about the impact of traffic-related pollution on indoor air quality of a naturally ventilated office building. The relationship between the linear pollutant source (i.e. the road) and the study building are explored by varying the distance from the roadway, the wall porosity, the windows location and the oncoming 
wind direction and velocity. What emerges is an exponential decline of indoor particles concentration with the distance from the roadway and the increase of the wind velocity. Again, the study focuses only on a single isolated building.

A different method for assessing the impact of traffic related pollution inside a generic naturally ventilated building has been used in ref. [32]. Here, a simple street canyon geometry has been deployed for CFD simulations with the aim of understanding how outdoor pollution would affect the indoor air quality of naturally ventilated buildings facing the canyon. The pressure and pollutant concentration fields are determined for the outdoor domain, while the ventilation fluxes and indoor pollutant concentration are worked out for an idealized two-room wide internal layout according to different windows opening percentages. No consideration is given to indoor thermal conditions.

The benefits of employing a natural ventilation strategy for new office buildings located in different Chinese climate zones have been estimated in terms of cooling energy savings in ref. [33]. First, the number of hours deemed suitable for NV purposes are worked out in a simplified way accounting for different outdoor pollutants by means of an Air Quality Index (AQI) defined in Chinese national air quality standards [34]. Then, energy simulations run in EnergyPlus revealed that the cooling energy savings achievable in different cities when natural ventilation is used might range between $8-78 \%$ depending on local weather and air quality of each city. The main drawbacks of such an approach appears to be the simplifications in appraising the NV potential and the single building scale used for the analysis.

Finally, Martins and Carrilho da Graça developed a two-stage methodology of increasing complexity to study the impact of airborne particle pollution on NV potential of office buildings located in Europe, US and Asia respectively [35-37]. This methodology first quantifies the number of hours deemed suitable for NV purposes as those occurrences when outdoor temperatures range from 10 to $26^{\circ} \mathrm{C}$ and outdoor PM2.5 concentration is lower than the geographically relevant annual threshold shown in Table 2. Then, dynamic thermal simulations in EnergyPlus are employed to get NV flow rates, indoor particulate matter concentrations and cooling energy needs.

Table 1. Summary of previous works

\begin{tabular}{|l|l|l|l|l|}
\hline Author & $\begin{array}{l}\text { Scale and } \\
\text { building } \\
\text { function }\end{array}$ & Method adopted & $\begin{array}{l}\text { Outdoor } \\
\text { pollutants }\end{array}$ & Output \\
\hline $\begin{array}{l}\text { Costanzo and } \\
\text { Donn [24] }\end{array}$ & $\begin{array}{l}\text { idealized urban } \\
\text { setting of office } \\
\text { buildings }\end{array}$ & $\begin{array}{l}\text { CFD simulations for } \\
\text { deriving Coefficients } \\
\text { of Pressure }(\mathrm{Cp}) \text { to be } \\
\text { passed to thermal } \\
\text { simulations }\end{array}$ & $\begin{array}{l}\mathrm{CO}_{2} \\
\text { coefficients of } \\
\text { pressure, air } \\
\text { change rates, } \\
\text { indoor thermal } \\
\text { conditions and } \\
\text { pollutant } \\
\text { concentrations }\end{array}$ \\
\hline
\end{tabular}




\begin{tabular}{|c|c|c|c|c|}
\hline $\begin{array}{l}\text { Ramponi et al. } \\
{[25]}\end{array}$ & $\begin{array}{l}\text { idealized urban } \\
\text { setting of office } \\
\text { buildings }\end{array}$ & $\begin{array}{l}\text { previous experimental } \\
\text { works for getting Cp } \\
\text { coefficients to be } \\
\text { passed to thermal } \\
\text { simulations }\end{array}$ & no & $\begin{array}{l}\text { air change rates, } \\
\text { cooling energy } \\
\text { needs }\end{array}$ \\
\hline $\begin{array}{l}\text { Cheung and Liu } \\
{[26]}\end{array}$ & $\begin{array}{l}\text { both an idealized } \\
\text { urban setting and } \\
\text { a single } \\
\text { residential } \\
\text { building }\end{array}$ & CFD simulations & no & $\begin{array}{l}\text { outdoor wind } \\
\text { velocity field, air } \\
\text { change rates }\end{array}$ \\
\hline Du et al [27] & $\begin{array}{l}\text { single residential } \\
\text { building }\end{array}$ & $\begin{array}{lr}\text { CFD and thermal } \\
\text { simulations validated } \\
\text { with on-site } \\
\text { measurements }\end{array}$ & no & $\begin{array}{l}\text { indoor wind } \\
\text { velocity and } \\
\text { thermal comfort } \\
\text { conditions }\end{array}$ \\
\hline $\begin{array}{l}\text { Al-Sallal et al. } \\
{[28]}\end{array}$ & $\begin{array}{l}\text { real urban setting } \\
\text { in Dubai (UAE) }\end{array}$ & CFD simulations & no & $\begin{array}{l}\text { outdoor wind } \\
\text { velocity field }\end{array}$ \\
\hline Yang et al. [29] & $\begin{array}{l}\text { real urban setting } \\
\text { in Singapore }\end{array}$ & $\begin{array}{l}\text { CFD simulations } \\
\text { validated with on-site } \\
\text { measurements }\end{array}$ & no & $\begin{array}{l}\text { outdoor thermal } \\
\text { comfort }\end{array}$ \\
\hline Park et al. [30] & $\begin{array}{l}\text { three buildings in } \\
\text { different sites in } \\
\text { Seoul (South } \\
\text { Korea) }\end{array}$ & on-site measurements & $\begin{array}{ll}\mathrm{CO}_{2} & \text { and } \\
\mathrm{PM} 2.5 & \end{array}$ & $\begin{array}{l}\text { indoor air change } \\
\text { rates and } \\
\text { pollutant } \\
\text { concentrations }\end{array}$ \\
\hline Tong et al. [31] & $\begin{array}{l}\text { generic isolated } \\
\text { building }\end{array}$ & \begin{tabular}{ll} 
CFD & \multicolumn{2}{c}{ simulations } \\
validated & with scale \\
models &
\end{tabular} & $\begin{array}{l}\text { different } \\
\text { PM } \\
\text { particles }\end{array}$ & $\begin{array}{lr}\text { indoor } & \text { and } \\
\text { outdoor } & \\
\text { concentrations of } \\
\text { different } \\
\text { sizes }\end{array}$ \\
\hline Yang et al. [32] & $\begin{array}{lr}\text { idealized } & \text { urban } \\
\text { setting } & \text { of } \\
\text { residential } & \\
\text { buildings } & \end{array}$ & $\begin{array}{lr}\text { CFD } & \text { simulations } \\
\text { validated } & \text { against } \\
\text { previous } & \text { water } \\
\text { channel and numerical } \\
\text { analysis results }\end{array}$ & $\mathrm{CO}$ & $\begin{array}{l}\text { outdoor pressure } \\
\text { and pollutant } \\
\text { concentrations } \\
\text { fields, indoor } \\
\text { pollutant } \\
\text { concentrations } \\
\text { and air change } \\
\text { rates }\end{array}$ \\
\hline Tong et al.[33] & $\begin{array}{ll}\text { single } & \text { office } \\
\text { building } & \end{array}$ & thermal simulations & $\begin{array}{l}\text { different } \\
\text { pollutants } \\
\text { by means of } \\
\text { an air } \\
\text { quality } \\
\text { index }\end{array}$ & $\begin{array}{l}\text { cooling energy } \\
\text { needs }\end{array}$ \\
\hline $\begin{array}{l}\text { Martins et al. } \\
{[35-37]}\end{array}$ & $\begin{array}{ll}\text { isolated } & \text { office } \\
\text { building } & \end{array}$ & thermal simulations & PM2.5 & $\begin{array}{l}\text { indoor } \\
\text { temperature, } \\
\text { cooling energy } \\
\text { needs }\end{array}$ \\
\hline
\end{tabular}

1

2 Table 2. PM2.5 limits according to different regulatory bodies

\begin{tabular}{|l|l|l|}
\hline $\begin{array}{l}\text { Regulatory } \\
\text { body }\end{array}$ & $\begin{array}{l}\text { Daily limit } \\
\left(\boldsymbol{\mu g m}^{-3}\right)\end{array}$ & $\begin{array}{l}\text { Annual limit } \\
\left(\boldsymbol{\mu g m}^{-3}\right)\end{array}$ \\
\hline WHO [38] & 25 & 10 \\
\hline China [39] & 75 & 35 \\
\hline
\end{tabular}

3

\section{$4 \quad 1.2$ Aim and objectives}

5 Among the (quite few) approaches found in the literature, the one proposed in refs. [35-37] appears 
the most detailed in dealing with the problem of determining the NV potential reductions due to outdoor pollution. Nevertheless, similarly to other studies discussed in the previous section, it does not take into account for any sheltering effects due to a highly dense urban layout. This means that it potentially overestimates the benefits from natural ventilation in providing a comfortable indoor environment. Further, the focus is on office buildings, which typically present a regular occupancy pattern and where occupants are less free to adapt to their environment in terms of opening of the windows to let in some fresh air.

This paper aims to develop a holistic method combining dynamic building thermal and urban environment CFD simulations to evaluate the natural ventilation potential in a dense urban setting considering the effect of air pollution. The pressure coefficients on building facades are derived from the actual urban morphology, while thermal simulations employed the EnergyPlus software for modelling a typical apartment flat located in the Yuzhong district in Chongqing municipality (China) after validation using on-site measured temperature data. The recorded hourly values of outdoor PM2.5 concentrations from one-year measurements were used for the assessment.

\section{Method}

The natural ventilation potential is worked out by means of thermal simulations in EnergyPlus aimed at estimating the number of hours when indoor thermal conditions are comfortable. Because this tool - as well as other well validated and widely used BES software - cannot directly account for the wind sheltering effects due to the surroundings, the simulation approach implemented makes use of urban CFD simulations in ANSYS to work out the Coefficients of Pressure (Cp) for every building surface. This information, together with hourly PM2.5 concentrations and weather variables recorded outdoor and with indoor temperatures measured for a typical apartment flat, is then passed to the BES software to validate the thermal model and thus appraise indoor comfort conditions (see the flowchart in Figure $1)$. 


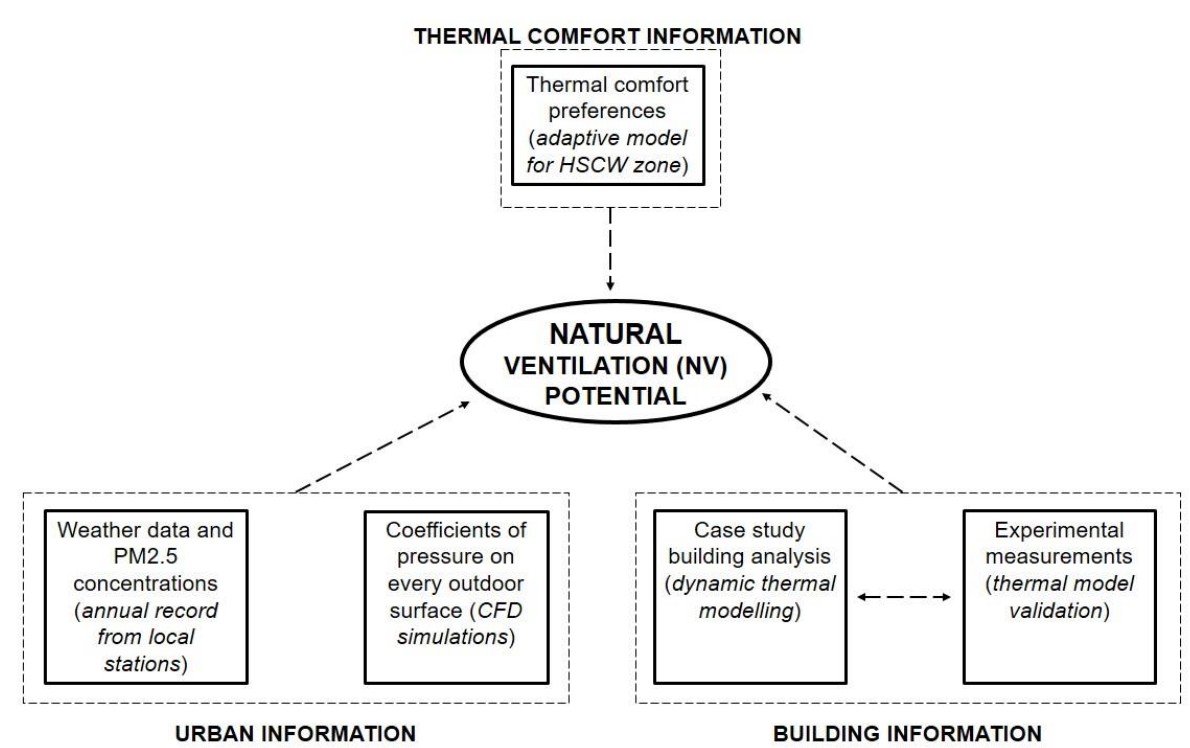

Figure 1. Flowchart of the method

The reduction of natural ventilation potential due to the presence of outdoor pollution is then discussed by comparison of the following scenarios:

1) SC_0: without natural ventilation (base case);

2) SC_1: natural ventilation is used whenever the indoor and outdoor temperature meet the conditions set by the control logic described in Section 3.2 and irrespective of PM2.5 concentration values;

3) SC_2: natural ventilation is employed only during those hours when the control logic conditions are met and when outdoor PM2.5 concentrations are lower than the annual Chinese threshold of $35 \mu \mathrm{gm}^{-3}$ [39];

4) $\mathrm{SC}_{-}$3: the same as $\mathrm{SC} \_2$ but adopting the more stringent $\mathrm{PM} 2.5$ threshold value set by WHO of $10 \mu \mathrm{gm}^{-3}[38]$.

\subsection{CFD modelling}

CFD simulations of the study area of the Yuzhong district in Chongqing city have been run using the commercial software ANSYS Fluent [40]. Within this area, a case study building representative of the common multi-story apartment typology has been selected for thermal analysis purposes (details are reported in Section 3.2). The computational domain used to enclose a volume big enough to appraise the sheltering effects from the surroundings has been set to $4100 \times 2600 \times 900 \mathrm{~m}^{3}$ (see Figure 
2). The inlet, lateral and upper boundaries are placed at a distance over $4 H_{\max }$ from the building complex, while the outlet boundary is located $8 H_{\max }$ far from the area of interest, being $H_{\max }$ the maximum building height of the domain [41].
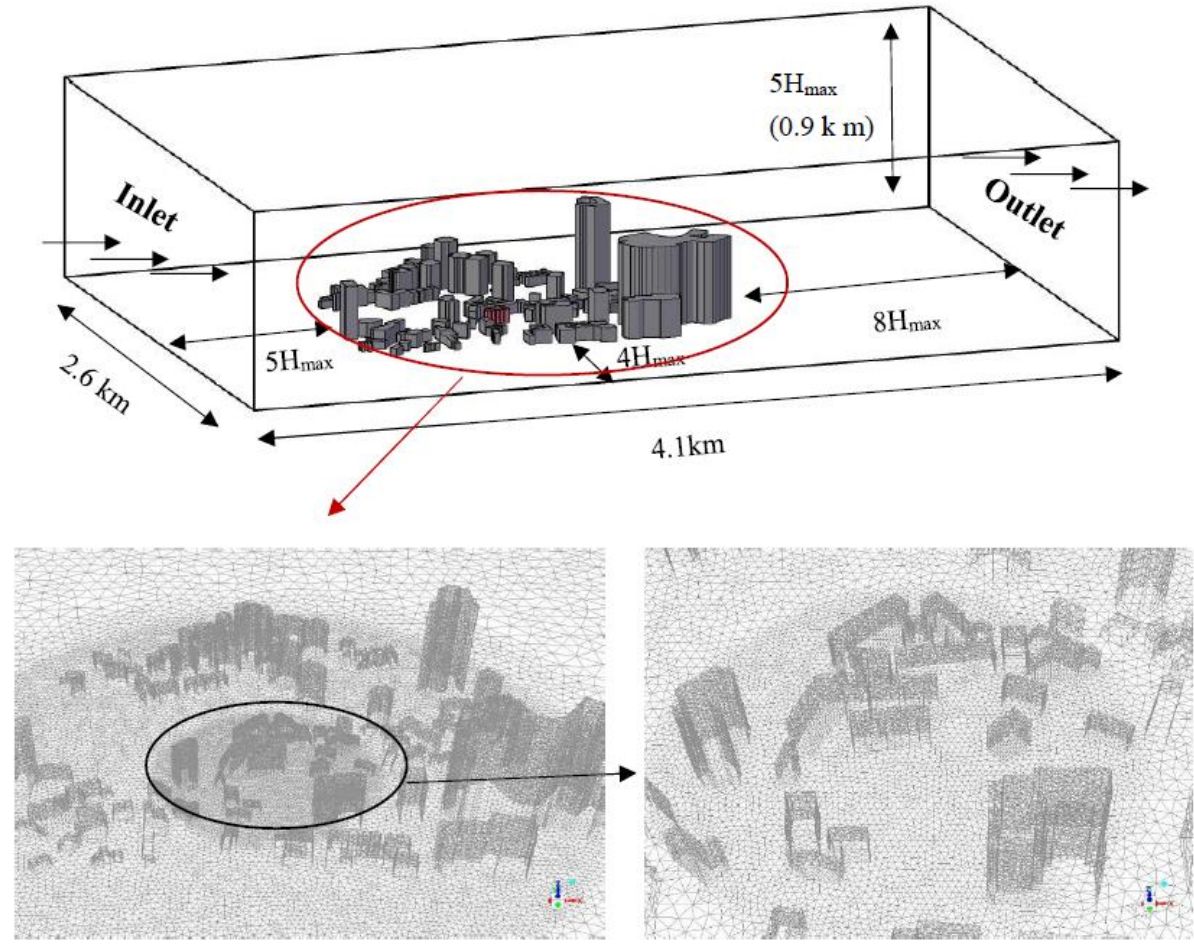

Figure 2. CFD computational domain (top) with a detail of the mesh geometry (bottom)

For the sake of keeping reasonable simulation times without affecting accuracy, an independence grid-size test has been carried out on the computed Coefficient of pressure $\left(C_{p}\right)$ values for a windward surface of a building located $1.1 \mathrm{~km}$ upstream. In particular, among the four mesh sizes listed in Table 3, mesh n.3 (unstructured tetrahedral mesh of 7391998 elements and 1240567 nodes refined around the study building using the partial encryption method) has been retained for the simulations because it secures $C_{p}$ values within a $\pm 5 \%$ difference if compared to those computed when using finer resolutions (see Figure 3).

Table 3. Mesh grids used for independence test

\begin{tabular}{|c|c|c|c|c|}
\hline Mesh n. & 1 & 2 & 3 & 4 \\
\hline $\begin{array}{c}\text { Number of } \\
\text { elements }\end{array}$ & 2135977 & 5460745 & 7319898 & 1034895 \\
\hline
\end{tabular}


$9 \quad \frac{\partial \bar{u}_{i}}{\partial x_{i}}=0$

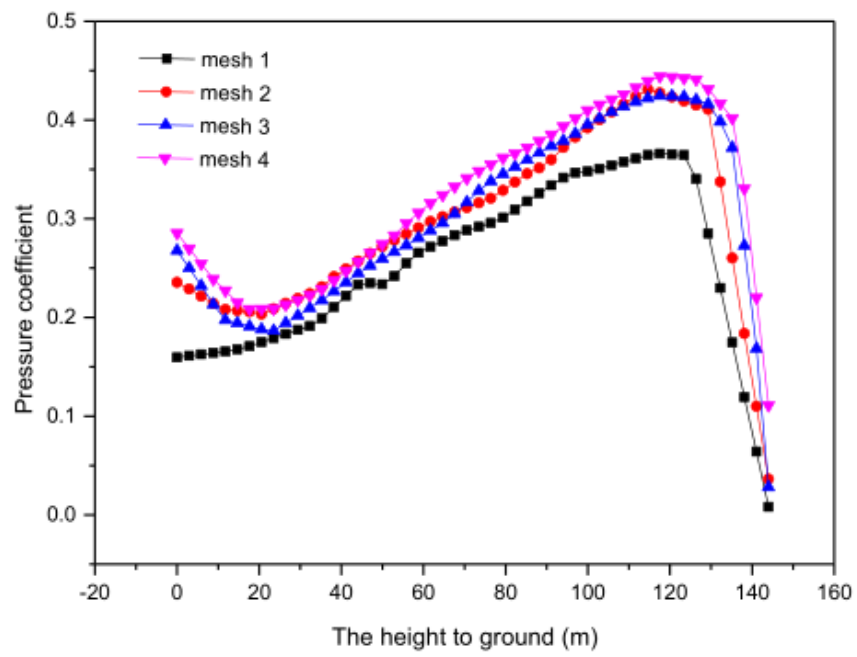

Figure 3. Mesh grid independence test

The ReNormalization Group (RNG) model has been chosen to solve the governing Navier-Stokes equations of continuity, momentum conservation, kinetic energy and turbulence dissipation (Eqs.14), discretized using the finite volume method and solved using the SIMPLE (Semi-Implicit Method for Pressure Linked Equations) algorithm:

$\bar{u}_{j} \frac{\partial \bar{u}_{i}}{\partial x_{j}}=-\frac{1}{\rho} \frac{\partial \bar{p}}{\partial x_{i}}+v \frac{\partial^{2} \bar{u}_{i}}{\partial^{2} x_{j}^{2}}-\frac{\partial}{\partial x_{j}}\left(\bar{u}_{i}^{\prime} \bar{u}_{j}^{\prime}\right)+\left(\frac{\rho-\rho_{0}}{\rho}\right) g_{i}$

$\bar{u}_{i} \frac{\partial k}{\partial x_{i}}=\frac{1}{\rho} \frac{\partial}{\partial x_{i}}\left(\alpha_{k} \mu_{e f f} \frac{\partial k}{\partial x_{i}}\right)+\frac{G_{b}}{\rho}+\frac{G_{k}}{\rho}-\varepsilon$

$\bar{u}_{i} \frac{\partial \varepsilon}{\partial x_{i}}=\frac{1}{\rho} \frac{\partial}{\partial x_{i}}\left(\alpha_{\varepsilon} \mu_{e f f} \frac{\partial \varepsilon}{\partial x_{i}}\right)+\frac{1}{\rho} C_{\varepsilon 1} \frac{\varepsilon}{k}\left(G_{k}+C_{\varepsilon 3} G_{b}\right)-\left[C_{\varepsilon 2}+\frac{C_{\mu} \rho \eta^{3}\left(1-\eta / \eta_{0}\right)}{1+\beta \eta^{3}}\right] \frac{\varepsilon^{2}}{k}$

Here $C_{\varepsilon 1}, C_{\varepsilon 2}, C_{\varepsilon 3}, C_{\mu}$ and $\eta_{0}$ are empirical constants obtained from experiments, which are set to 1.42 , $1.68,0.012,0.0845$ and 4.38 respectively according to refs. [42-43].

The Standard $k-\varepsilon$ turbulence model was employed because it can deal very well with flows having a great bending degree of streamline. Further, it has been shown from previous works that it can accurately predict the coupled indoor/outdoor airflows [44-49].

For what concerns the inlet boundary conditions, these are input by means of a user defined function file where the wind velocity profile $u(z)\left(\mathrm{ms}^{-1}\right)$ is defined using the power law formulation: 
$1 \quad u(z)=u_{o}\left(\frac{z}{z_{0}}\right)^{\alpha}$

2 being $u_{0}$ the wind speed at reference height $z_{0}(10 \mathrm{~m}$ above the ground as got from a local weather station) and $\alpha$ an empirically derived coefficient set to 0.3 according to the terrain roughness [50]. Null pressure values have been set at the outlet and no-slip condition (i.e. velocity equal to zero) is assumed for the ground and building surfaces, while symmetric boundary conditions (i.e. variable gradient equals zero) are set for the other sides and the top of the computational domain.

\subsection{Thermal modelling and comfort assessment}

Among a variety of BES software currently available, the largely validated EnergyPlus v8.4 is chosen for its capability in modelling the mass and heat transfer processes in buildings [51]. In particular, natural ventilation is modeled by using the nodal approach provided by the embedded Airflow Network Module that proved to be very efficient in estimating both wind-induced pressure differences and stack effects due to temperature differences at the building openings [52-53].

More in detail, the airflow through the building is modelled in analogy with the flow of current in an electrical circuit, where the nodes are defined according to known pressure values, and the resistances to the airflow represented by the openings (external and internal) are defined mainly by means of a discharge coefficient.

Given two nodes $i$ and $j$ the total pressure difference $\Delta P(\mathrm{~Pa})$ among them is then calculated as:

$$
\Delta P=P_{i}-P_{j}+P_{S}+P_{W}
$$

where $P_{i}$ and $P_{j}$ are the local pressure values and $P_{S}$ and $P_{W}$ are the stack and wind induced pressures. The stack pressure $P_{S}(\mathrm{~Pa})$ is calculated according to the following equation:

$$
P_{S}=-\rho g T_{\text {ins }}\left(h_{\text {out }}-h_{\text {ins }}\right)\left(\frac{1}{T_{\text {out }}}-\frac{1}{T_{\text {ins }}}\right)
$$

being $\varrho$ the air density $\left(\mathrm{kgm}^{-3}\right), g$ the acceleration due to gravity $\left(\mathrm{ms}^{-2}\right), T_{\text {ins }}$ and $T_{\text {out }}$ the temperature at inside/outside of air stack (K) and $h_{\text {ins }}$ and $h_{\text {out }}$ their heights above datum (m).

The wind pressure $P_{W}(\mathrm{~Pa})$ is determined according to Bernoulli's equation under the assumption of no height changes and pressure losses: 


$$
P_{W}=C_{P} \rho \frac{u_{0}^{2}}{2}
$$

being $C_{P}$ the Coefficient of Pressure at the windows height (dimensionless) derived with respect to a reference wind velocity $u_{0}\left(\mathrm{~ms}^{-1}\right)$ from CFD simulations as already detailed in the previous section, and calculated with a step of 45 degrees. This external coupling approach thus uses steady-state CFD simulations (one for every wind direction) to derive $C_{p}$ values for every surface of the model, and then passes these values to the thermal simulations as the exchange variables. The corresponding airflows, accounting also for the presence of a generic air contaminant (PM2.5 in our case), are calculated according to other relevant equations that the reader can find in the Engineering Reference book of the software.

Thermal comfort conditions are assessed according to the adaptive comfort theory that is widely recognized as the standard to follow when people are free to adapt to their environment, as in the case of naturally ventilated buildings [7, 54].

Follow on this approach, the adaptive Predicted Mean Vote ( $a P M V)$ defined in [55] was used in this study to evaluate thermal comfort:

$$
\mathrm{a} P M V=\frac{P M V}{(1+\lambda P M V)}
$$

Here $\lambda$ is the dimensionless adaptive coefficient, determined according to Chongqing local climate conditions as suggested in ref. [55], while PMV is the Predictive Mean Vote as for the original Fanger's formulation [56].

The other parameters to be input into the $a P M V$ model were obtained from the field survey carried out in the HSCW zone and reported in [9]. More in detail, the mean air velocity is set to $0.1 \mathrm{~ms}^{-1}$, while the mean radiant temperature is assumed to be equal to the mean indoor air temperature (found to be $22^{\circ} \mathrm{C}$ ) under the assumption of predominant convective heat transfer in free running buildings. The clothing insulation level varies from a minimum of 0.22 clo in summer to a maximum of 1.83 clo in winter, and the metabolic rate is set at 1 met throughout the year (sedentary activity).

The boundaries for comfort conditions in terms of relative humidity and indoor temperature are listed in Table 4 and calculated for $a P M V$ values ranging from -0.5 to 0.5 , which means that the thermal environment evaluation grade is assessed as I and $90 \%$ of occupants are satisfied with it according to GB 50736 Standard [57]. 
Table 4. Comfort boundaries in HSCW zone

\begin{tabular}{|l|c|c|c|c|c|c|}
\hline $\begin{array}{l}\text { Relative } \\
\text { humidity } \\
(\%)\end{array}$ & 30 & 40 & 50 & 60 & 70 & 80 \\
\hline $\begin{array}{l}\text { Indoor } \\
\text { temperature } \\
\text { range }\left({ }^{\circ} \mathbf{C}\right)\end{array}$ & $18.42-28.63$ & $18.10-28.52$ & $17.85-28.32$ & $17.72-28.12$ & $17.67-27.90$ & $17.54-27.69$ \\
\hline
\end{tabular}

2

Finally, the control logic implemented for allowing the opening of the windows is the following:

$$
\left\{\begin{array}{l}
10<T_{\text {outdoor }}<28 \\
T_{\text {indoor }}-T_{\text {outdoor }}>2 \\
\text { PM2.5 concentration }<\text { threshold }
\end{array}\right.
$$

The first two conditions are applied for al NV scenarios (i.e. SC_1, SC_2 and SC_3), while the last one just for scenarios SC_2 and SC_3 according to thresholds set by China and WHO respectively and reported in Table 2.

\section{Description of the case study}

\subsection{Local climate and PM2.5 concentration}

The study area is the Yuzhong district in Chongqing, a city that belongs to the Hot Summer and Cold Winter (HSCW) climate zone of China according to the Standard of Climate Regionalization for Architecture [7]. To give the reader an idea of the climate variables mostly affecting NV potential, as well as of the magnitude of PM2.5 concentrations, Table 5 reports on the average, maximum and minimum values of outdoor dry bulb temperature, wind speed and direction, and PM2.5 concentrations for different periods of the year. This data refers to year 2017 and has been gathered from Shapingba district weather station, which has been used also for running the annual simulations. For what concerns PM2.5 concentrations, they have been collected from a station recording different airborne pollutants located in Daping residential district.

If looking at this data, it appears that climate conditions are not so favorable for natural ventilation because of quite high average temperatures during transition and summer periods $\left(19.3\right.$ and $18.8{ }^{\circ} \mathrm{C}$ respectively), low wind speeds (a consistently low average value of around $1.3 \mathrm{~m} / \mathrm{s}$ throughout the year) and high PM2.5 concentrations (seasonal averages always higher than $27.4 \mu \mathrm{gm}^{-3}$ ).

\footnotetext{
Table 5. Main climate variables for natural ventilation assessment
} 


\begin{tabular}{|c|c|c|c|c|c|}
\hline Time period & $\begin{array}{c}\text { Statistical } \\
\text { variable }\end{array}$ & $\begin{array}{c}\text { Dry bulb } \\
\text { temperature } \\
\left({ }^{\circ} \mathrm{C}\right)\end{array}$ & $\begin{array}{c}\text { Wind speed } \\
\left(\mathrm{ms}^{-1}\right)\end{array}$ & $\begin{array}{c}\text { Wind } \\
\text { direction } \\
\text { (clockwise } \\
\text { degrees from } \\
\text { north) }\end{array}$ & $\begin{array}{c}\text { PM2.5 } \\
\text { concentrations } \\
\left(\mu \mathrm{gm}^{-3}\right)\end{array}$ \\
\hline \multirow{3}{*}{$\begin{array}{l}\text { Summer }^{*} \text { (from } \\
\text { June } 15^{\text {th }} \text { to } \\
\text { August } 31^{\text {st }} \text { ) }\end{array}$} & AVG & 30.4 & 1.5 & 316 & 27.4 \\
\hline & MAX & 41.4 & 6.3 & \multirow{2}{*}{ - } & 92 \\
\hline & MIN & 18.7 & 0 & & 0 \\
\hline \multirow{3}{*}{$\begin{array}{l}\text { Winter }^{*} \quad \text { (from } \\
\text { December } 1^{\text {st }} \text { to } \\
\left.\text { February } 28^{\text {th }}\right)\end{array}$} & AVG & 10.1 & 1.2 & 338 & 78.1 \\
\hline & MAX & 20.3 & 5.6 & \multirow{2}{*}{ - } & 209 \\
\hline & MIN & 4.7 & 0 & & 0 \\
\hline \multirow{3}{*}{$\begin{array}{l}\text { Transition } \\
\text { period (the } \\
\text { remaining of the } \\
\text { year) }\end{array}$} & AVG & 19.3 & 1.3 & 340 & 35.5 \\
\hline & MAX & 35.3 & 4.9 & \multirow[b]{2}{*}{-} & 138 \\
\hline & MIN & 7.6 & 0 & & 0 \\
\hline \multirow{3}{*}{ Annual } & $\mathrm{AVG}$ & 18.8 & 1.3 & 335 & 44.3 \\
\hline & MAX & 41.4 & 6.3 & \multirow{2}{*}{ - } & 209 \\
\hline & $\mathrm{MIN}$ & 4.7 & 0 & & 0 \\
\hline
\end{tabular}

4 A better insight can be achieved by analyzing the frequency distribution of these variables as reported 5 in Figure 4: although outdoor temperatures vary quite randomly all the year, the wind shows a clear 6 pattern that rebates the predominance of low velocities - with almost half of the year experiencing 7 speeds between 1 and $1.6 \mathrm{~m} / \mathrm{s}$ - and north-westerly directions.

8 As far as PM2.5 concentrations are concerned, their values are almost always higher than $10 \mu \mathrm{gm}^{-3}$ 9 (the daily average threshold set by WHO), being in the range of 10 to $50 \mu \mathrm{gm}^{-3}$ for about $56 \%$ of the 10 time and with peak values as high as $209 \mu \mathrm{gm}^{-3}$.
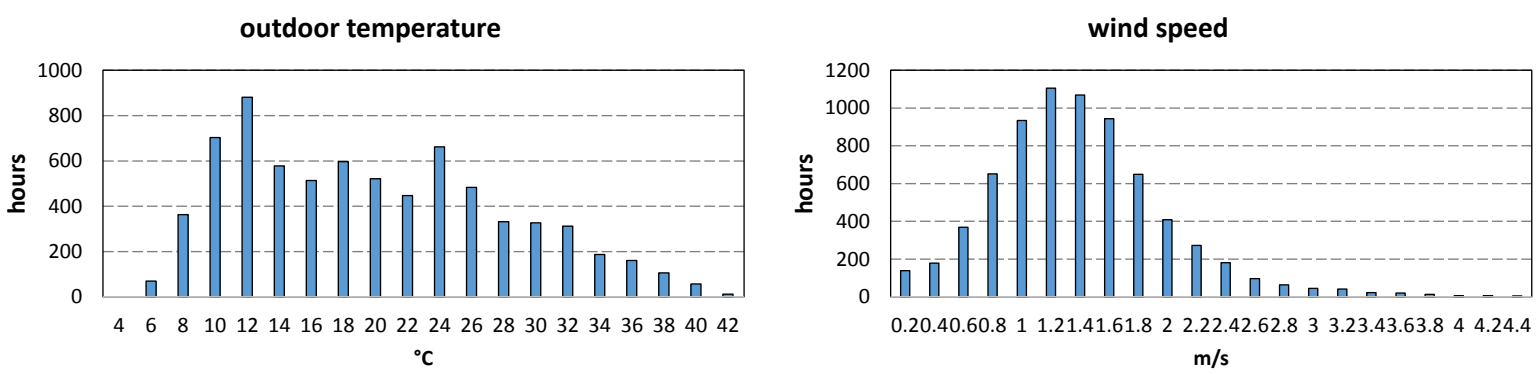

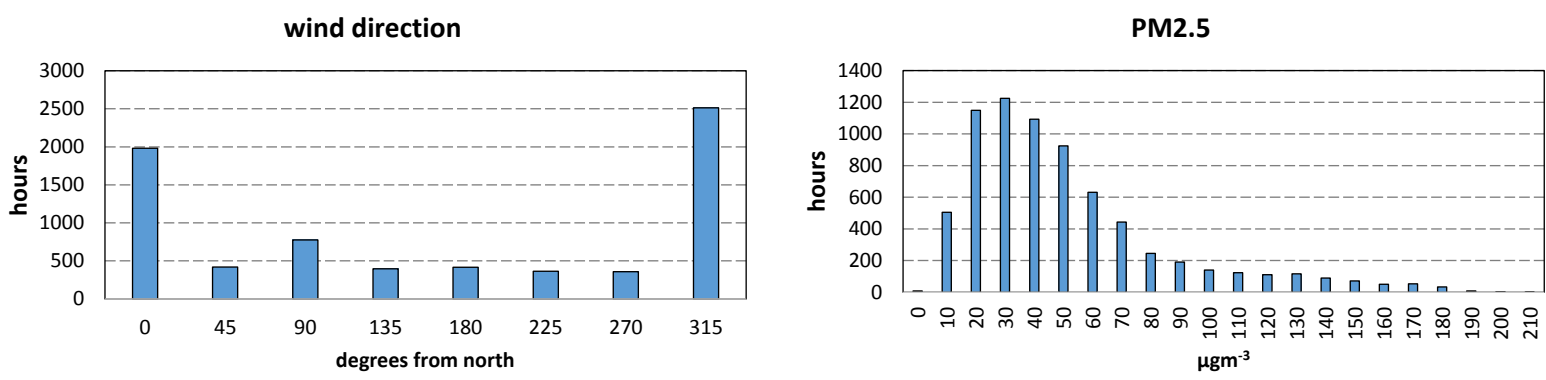

Figure 4. Frequency distribution of key climate variables and of PM2.5 airborne pollutant

\subsection{A typical apartment flat in the Yuzhong district}

In terms of urban characteristics, the study area has a good mixture of building functions: residential buildings accounts for $62 \%$ of the total, mixed-use buildings (i.e. buildings hosting both residential and other uses) for $15 \%$ and other non-residential buildings for $22 \%$ respectively.

Given the range of functions and construction ages found within this zone, as well as the availability of empty spaces for new buildings, this area is deemed to well represent the complexity found in developing Chinese cities and thus has been chosen as a case study.

The 3D model used for CFD simulations was created based on the built area footprints gathered from Google Maps views, and the building heights retrieved from a ground survey carried out during 2015. From Figure 5 it is possible to appreciate how the tallest buildings (mainly offices and commercial premises) are located in the latest development area of the site (eastern part), while the oldest one mainly hosts residential buildings and some schools.

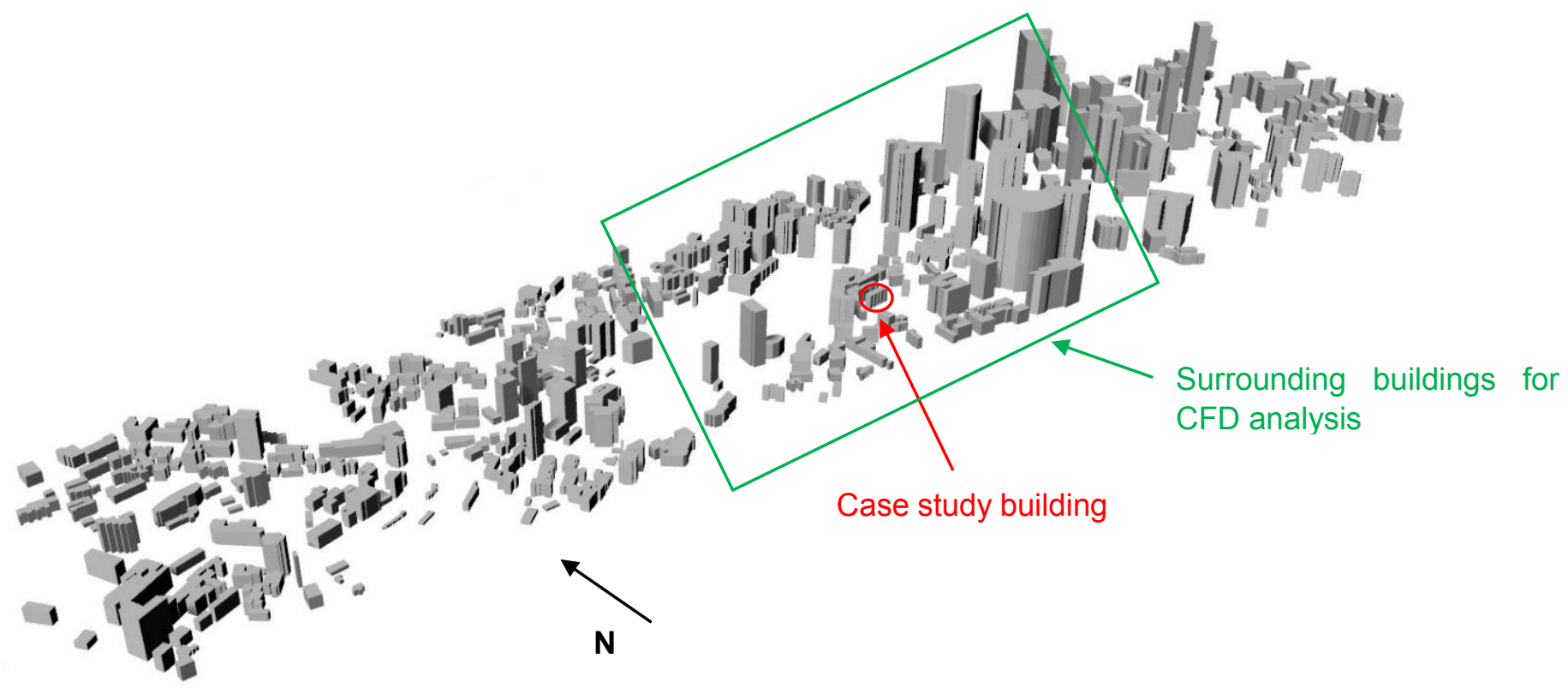

Figure 5. Axonometric view of the 3D model of the Yuzhong district with the case study building highlighted in red and the CFD computational domain highlighted in green 
2 The case study building is highlighted in circle and represents a multi-story apartment block located within the urban stripe surveyed in 2015. In the study area, there are many buildings of the same type in terms of both architectural and construction characteristics, thus the building chosen can be considered representative of them [59-60]. Under these premises, and thanks to an agreement with the owners, an apartment flat located on the $8^{\text {th }}$ floor has been surveyed and measured from August to September 2017 in terms of indoor temperature, relative humidity and air velocity. The aim is to have experimental data to carry out the validation process described in the next section. The flat is composed of a bedroom exposed due to north, a kitchen and an empty room (hereafter-called storage room) that faces due to south, and a living room with a bathroom in the middle (see Figure 6). The total net floor area is around $43 \mathrm{~m}^{2}$, the floor to ceiling height is $2.8 \mathrm{~m}$ while the window to wall ratio is $30 \%$ in the bedroom and storage room and around $44 \%$ in the living room respectively.
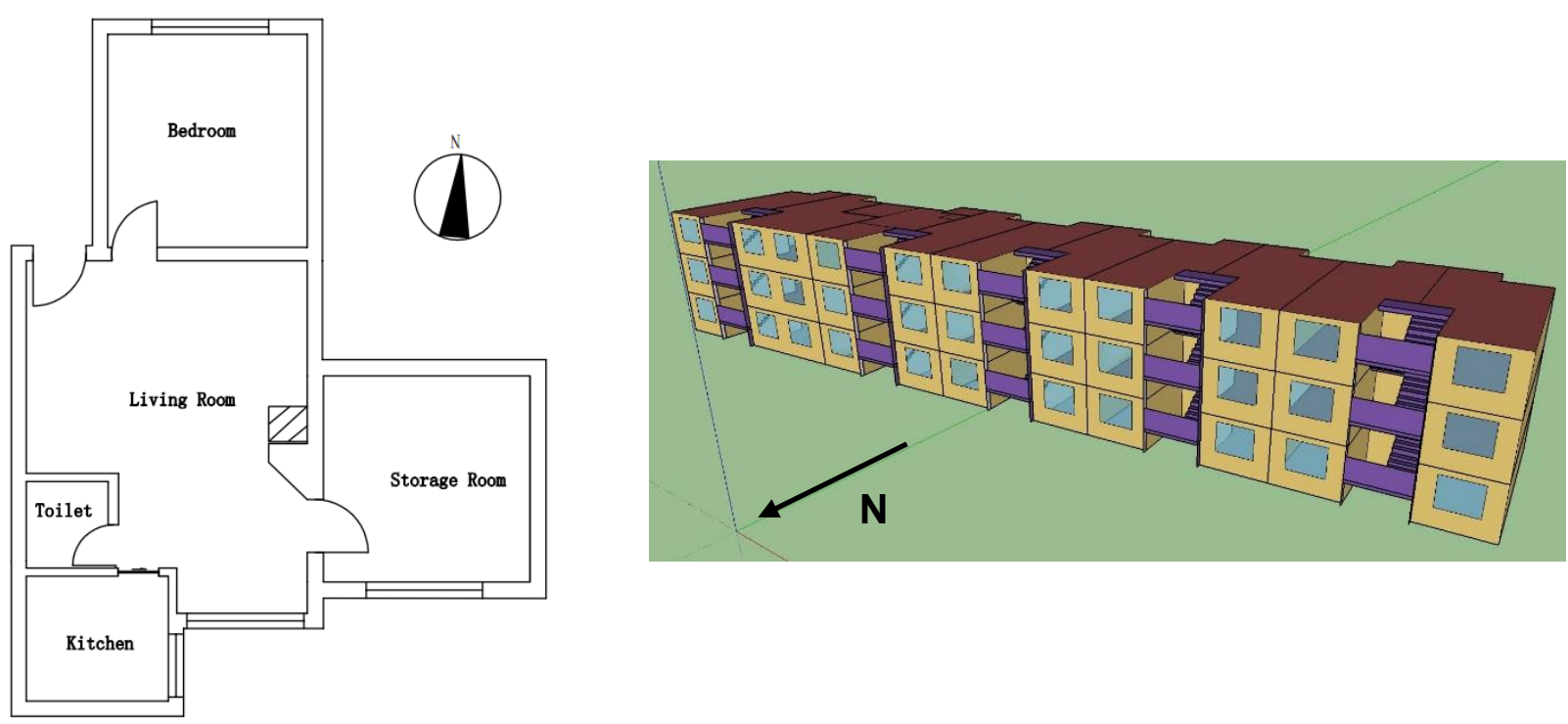

Figure 6. Plan view of the apartment flat (on the left) and of the thermal model (on the right)

As for constructions, outer walls are made of concrete cellular blocks covered by an EPS insulation layer and a cement mortar layer externally, and by a cement plaster layer inside. Floors are made of a reinforced concrete slab covered with a cement mortar layer on both faces and by tiles on the walkable side, while internal partitions are made of hollow clay bricks covered on both sides by a cement mortar layer. Finally, single-glazed sliding windows with an aluminum frame are used in all 
1 the rooms (see Figure 7). The resulting U-values are $1.0 \mathrm{Wm}^{-2} \mathrm{~K}^{-1}$ for the walls, $3.8 \mathrm{Wm}^{-2} \mathrm{~K}^{-1}$ for the

2 floors and $5.7 \mathrm{Wm}^{-2} \mathrm{~K}^{-1}$ for the windows (with a solar heat gain coefficient of 0.85 ) respectively.

3
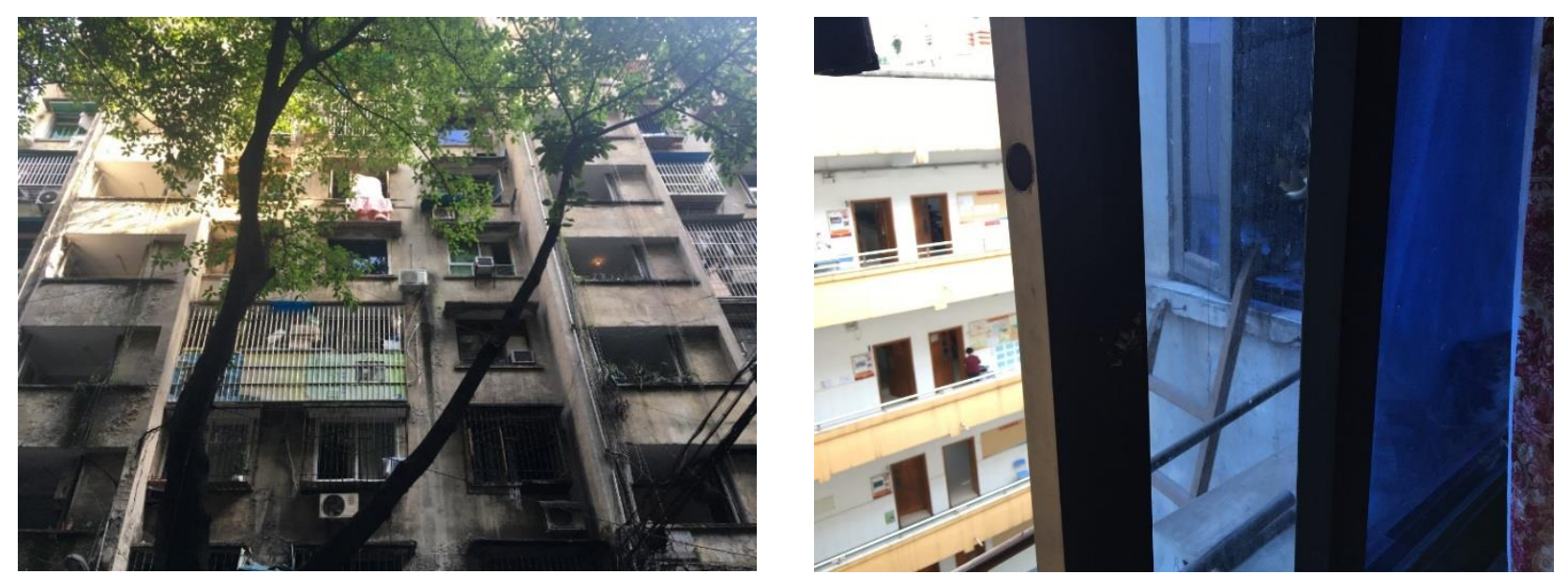

Figure 7. Outside view of the building (on the left) and detail of the sliding window (on the right)

\subsection{Experimental campaign and validation of the thermal model}

The sensors have been placed in the bedroom, living room and storage room at the same time and for all the measurement period in order to compare indoor conditions in different rooms. Surface temperatures and heat fluxes have been recorded on the outer walls provided with windows (see Figure 6), while indoor temperatures, relative humidity values, $\mathrm{CO}_{2}$ concentrations and air velocity measurements have been taken at $0.8 \mathrm{~m}$ from the floor and at the center of the rooms approximately. A summary of the instruments used, comprehensive of the instrument name, measurement range and accuracy range is provided in Table 6.

Table 6. Instruments details

\begin{tabular}{|l|l|l|l|}
\hline Measured variable & Instrument name & Measurement range & Accuracy range \\
\hline \multirow{2nnn}{*}{ Temperature } & \multirow{3}{*}{ Telaire TEL-7001 } & $0-50{ }^{\circ} \mathrm{C}$ & $\pm 1{ }^{\circ} \mathrm{C}$ \\
\cline { 4 - 4 } & & $0-95 \%$ & $\pm 2.5 \%$ \\
\cline { 3 - 4 } & & $0-4000 \mathrm{ppm}$ & $\pm 50 \mathrm{ppm}$ \\
\hline $\mathrm{CO}_{2}$ & HOBO T-DCI-F900-S-O & $0.15-5 \mathrm{~ms}^{-1}$ & $\pm 0.05 \mathrm{~ms}^{-1}$ \\
\hline Air velocity & K-type thermocouple & $-200-1372{ }^{\circ} \mathrm{C}$ & $\pm\left(0.15 \%+1^{\circ} \mathrm{C}\right)$ \\
\hline Surface temperature & HFPO1 & $-2000-2000 \mathrm{Wm}^{-2}$ & $\pm 3 \%$ \\
\hline Heat flux & &
\end{tabular}

During the measurement period, the storage room was always unoccupied, while from time to time a 
person has been using the bedroom and the other rooms. This is why, in order to avoid disturbing effects due to human behavior, the validation of the thermal model built in EnergyPlus has been carried out considering the storage room and the living room only. More specifically, simulated indoor temperatures have been compared with measured ones for one-week period (from August 21 to August 27 on 2017). The walls adjoining with the other flats are taken as adiabatic (i.e. no heat transfer is assumed through them because of very similar indoor conditions), while allowing heat transfer with the lower and upper floors through the ceiling and the floor. The outdoor conditions used are those recorded from the Shapingba weather station for the corresponding measurement days because it was not possible to install an outdoor weather station locally. Furthermore, a fixed infiltration rate of $1 \mathrm{ACH}$ is assumed for simulations according to the value suggested in the building standard in force at the period of construction of the flat [57].

The results of the validation exercise are shown in Figure 8, where it is possible to appreciate how well the simulated temperatures (dotted orange lines) follow the trend of the measured temperatures (solid blue lines) in both the living room and storage room. Peak differences, which keep always below $1.8^{\circ} \mathrm{C}$, are mainly imputable to the weather data used.
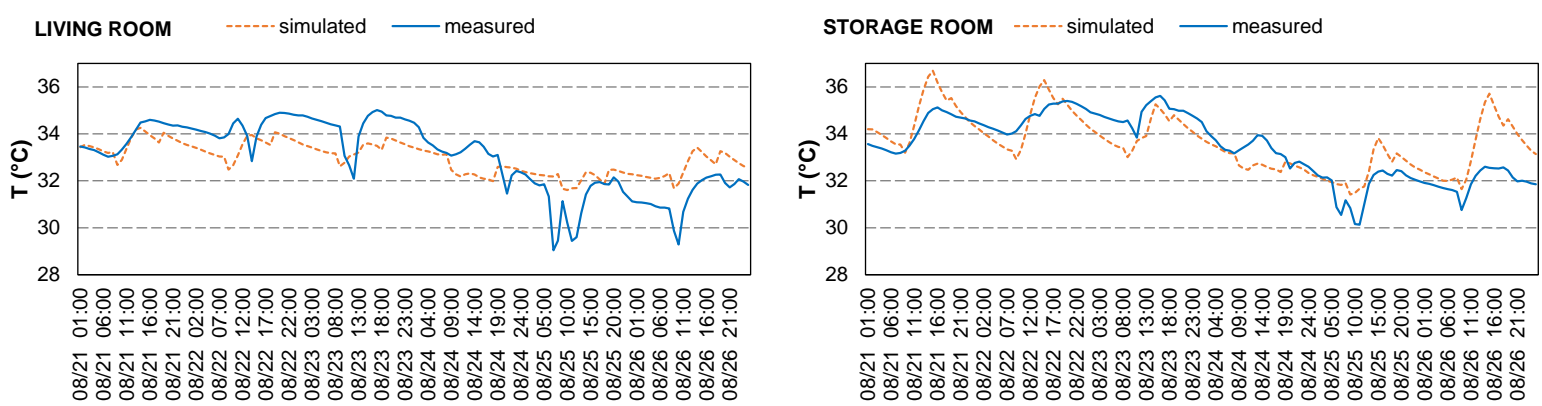

Figure 8. Comparison between measured (solid blue line) and simulated (dotted orange line) indoor temperatures for the living room and the storage room

To better substantiate these results, statistical indicators such as the Root Mean Square Error (RMSE), Pearson coefficient, Mean Bias Error (MBE) and average measured/simulated temperatures have been calculated. The results of these calculations, reported in Table 7, show a good agreement between the two sets of data so the model is considered validated and used for running the scenario analysis described in Section 3.

Table 7. Statistical indicators of the calibration process

\begin{tabular}{|l|l|l|}
\hline & Living room & Storage room \\
\hline RMSE & $3 \%$ & $3 \%$ \\
\hline Pearson coefficient & 0.78 & 0.74 \\
\hline
\end{tabular}




\begin{tabular}{|l|l|l|}
\hline MBE & $0 \%$ & $-1 \%$ \\
\hline Average measured $\left({ }^{\circ} \mathrm{C}\right)$ & 33.04 & 33.46 \\
\hline Average simulated $\left({ }^{\circ} \mathrm{C}\right)$ & 32.97 & 33.66 \\
\hline
\end{tabular}

\section{Results}

\subsection{Cp variability within the urban context}

The distribution of the coefficients of pressure for the buildings within the domain described in Section 2.1 is shown in Figure 9 in a false color scale format according to different wind directions. The highest values achievable for windward conditions (i.e. the positive values depicted in a scale of green to red colors) are around 0.552 and occur for north-westerly directions (315 degrees, bottom right picture), which according to the wind potential analysis carried out in Section 3.1 is also the predominant wind direction. As expected, if checking the graphs reported in Figure 9 for all wind directions, the peak values (positive for windward conditions and negative for leeward conditions) are always achieved by the tallest buildings located on the right hand size of the domain. This happens because they are not sheltered from the surroundings while, conversely, the study building is located approximately in the middle of the domain and it is surrounded by buildings of similar height. Under these circumstances, it can be considered representative of these premises in terms of peak values achievable: in fact, a deeper look into Figure 9 allows identifying a consistently lower distribution of the coefficients of pressure for all these buildings, being always in the range of -0.170 to 0.120 for every wind direction.

This means that, for the case study area, the sheltering effects can easily lower the natural ventilation potential by a factor of up to four, an aspect that needs further investigation. In fact, along with the reductions presented in this section that depend on the combined effect of wind direction and urban morphology, the specific building layout - in terms of windows orientation and height above the ground, as well as protrusions and recessions from the façade plane - can influence the pressure distribution and thus the potential for exploiting wind-driven natural ventilation. These factors will be dealt with in the next section. 
1
2

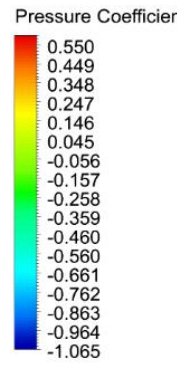

$\left\lfloor 0^{\circ}\right.$
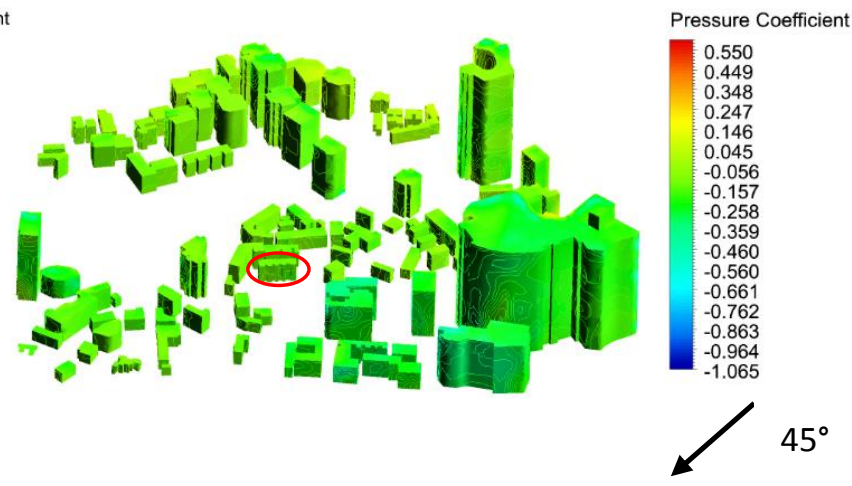

Pressure Coefficient $5^{\circ}$

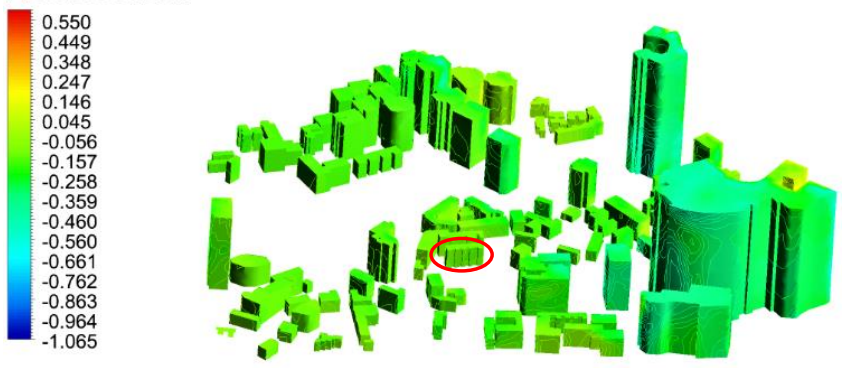

Pressure Coefficient
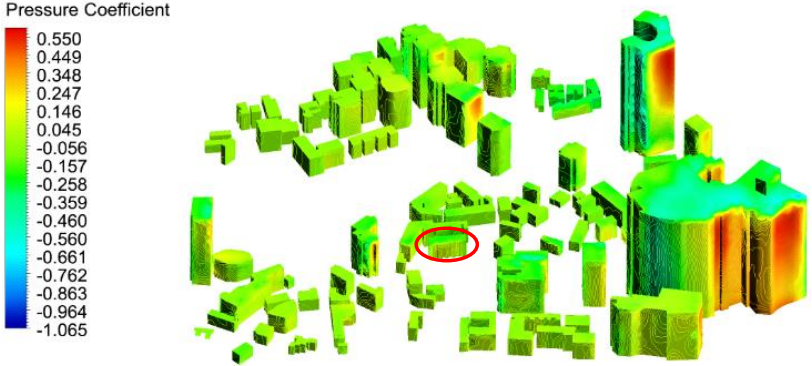

$135^{\circ}$

$90^{\circ}$

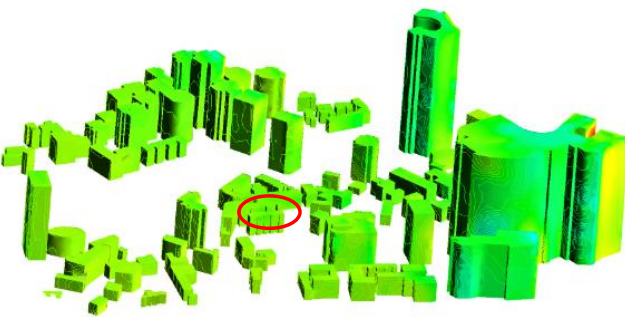

Pressure Coefficient

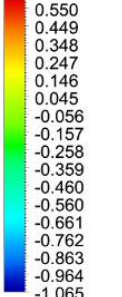

$90^{\circ}$
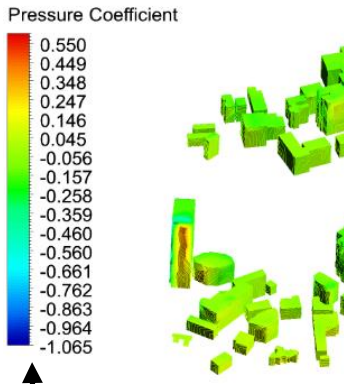

5
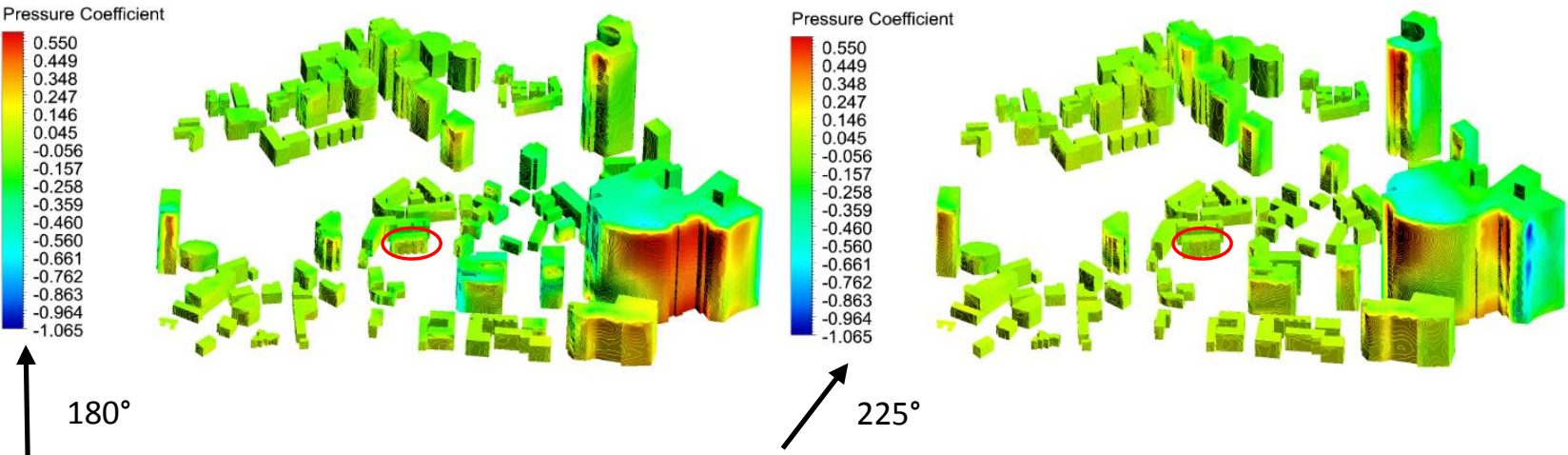

Pressure Coefficient
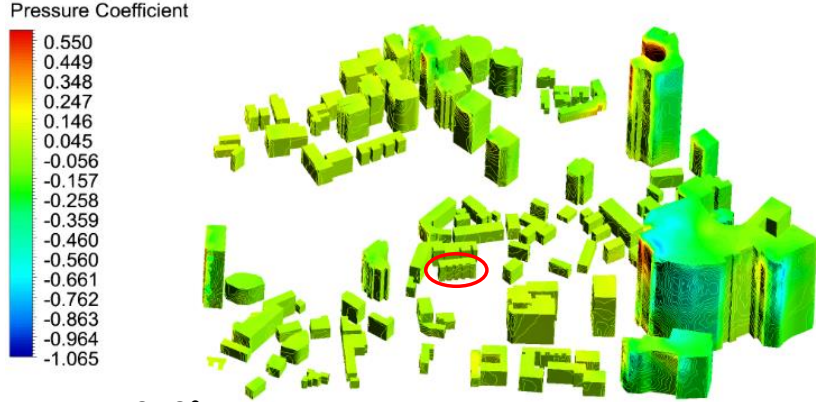

$270^{\circ}$

8

Figure 9. Coefficient of pressure distribution in the urban setting according to different wind directions (study building is encircled)

\subsection{Cp variability within the study building}

The study flat presents a window due to east located in the kitchen, two windows exposed due to south (one in the living room and one in the storage room) and one facing north located in the bedroom 
1 (see Figure 6 for the internal layout of the flat). Despite the different orientations, the values achieved

2 by the coefficients of pressure in the kitchen, living room and storage room are almost identical for

3 every wind direction as shown in Figure 10. These rooms are under negative pressure when the wind blows from northwesterly to east directions (i.e. for directions comprised between 315 and 90 degrees according to the chosen reference system), while being under positive pressure for the remaining directions. The maximum $C_{p}$ value achieved under negative pressure is -0.154 , whereas under positive pressure is of 0.064 .

8 A different pattern is instead recorded for the bedroom (yellow line with diamond markers in Figure 10), which according to CFD simulations is always under negative pressure and shows the highest coefficient of pressure value when the wind blows from south (around -0.190 at 180 degree), and the lowest for westerly direction (-0.018 at 270 degree).

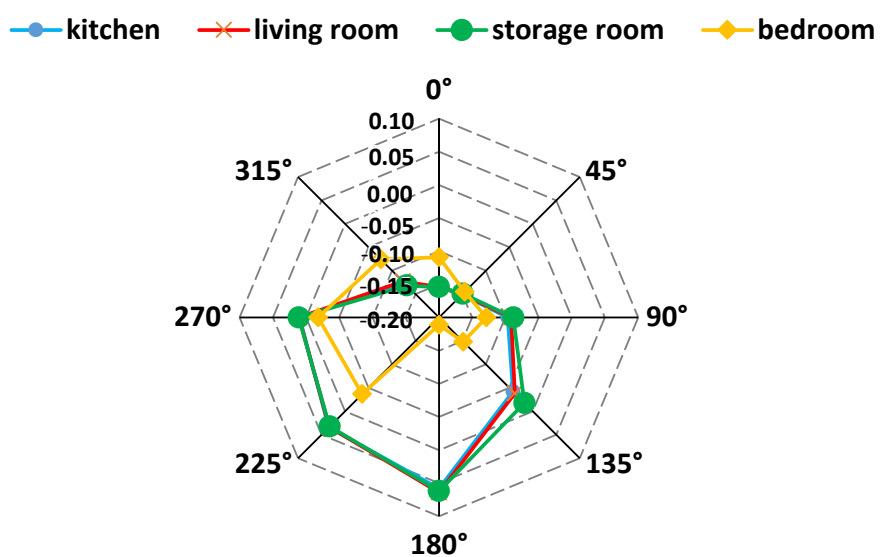

Figure 10. Coefficient of pressure distribution in the study flat as a function of room orientation and wind direction

In order to understand the variability of the coefficients of pressure not only with wind directions and with window orientation but also with the height from the ground, Table 8 reports their values for every floor of the building by highlighting those achieved in the study flat in grey color.

Here, it is worth to notice that it is not possible to find a common height for the neutral plane for every wind direction (i.e. that height from the ground above which the airflow inside the building reverses its direction). Indeed, for the kitchen, the living room and the storage room, this plane seems located around the eleventh floor (where $C_{p}$ change their sign) for wind directions between 180 and 270 degrees, whereas the remaining directions are always under negative pressure (negative sign of $\left.C_{p}\right)$. For what concerns the bedroom, the windows are always under negative pressure, and the variability of the coefficients of pressure strongly depends on the wind direction, maybe because it is 
1 this side of the building the one mostly affected from the sheltering action of the surroundings. In this

2 case, the maximum coefficient of pressure is achieved when the wind blows from southeast (135

3 degrees, variability with height of around 33\%), while the minimum when it blows from south (180

4 degrees, variability with height of less than $3 \%$ ).

5

6

Table 8. Coefficient of pressure distribution with building height and wind direction (the row highlighted refers to the study floor)

\begin{tabular}{|c|c|c|c|c|c|c|c|c|}
\hline \multicolumn{9}{|c|}{ kitchen } \\
\hline floor & $0^{\circ}$ & $45^{\circ}$ & $90^{\circ}$ & $135^{\circ}$ & $180^{\circ}$ & $225^{\circ}$ & $270^{\circ}$ & $315^{\circ}$ \\
\hline 1 & -0.154 & -0.138 & -0.094 & -0.015 & 0.111 & 0.084 & 0.026 & -0.105 \\
\hline 2 & -0.154 & -0.140 & -0.095 & -0.018 & 0.106 & 0.069 & 0.025 & -0.107 \\
\hline 3 & -0.157 & -0.140 & -0.095 & -0.023 & 0.101 & 0.054 & 0.023 & -0.109 \\
\hline 4 & -0.156 & -0.141 & -0.095 & -0.026 & 0.093 & 0.041 & 0.022 & -0.112 \\
\hline 5 & -0.158 & -0.144 & -0.094 & -0.028 & 0.079 & 0.035 & 0.020 & -0.116 \\
\hline 6 & -0.157 & -0.147 & -0.093 & -0.033 & 0.071 & 0.035 & 0.017 & -0.119 \\
\hline 7 & -0.154 & -0.149 & -0.093 & -0.038 & 0.066 & 0.037 & 0.014 & -0.123 \\
\hline 8 & -0.153 & -0.151 & -0.096 & -0.042 & 0.058 & 0.035 & 0.010 & -0.129 \\
\hline 9 & -0.151 & -0.152 & -0.100 & -0.047 & 0.048 & 0.031 & 0.006 & -0.150 \\
\hline 10 & -0.148 & -0.154 & -0.104 & -0.066 & 0.018 & 0.021 & 0.002 & -0.169 \\
\hline 11 & -0.146 & -0.153 & -0.108 & -0.095 & -0.005 & 0.008 & -0.003 & -0.172 \\
\hline 12 & -0.142 & -0.145 & -0.116 & -0.139 & -0.118 & -0.014 & -0.009 & -0.152 \\
\hline \multicolumn{9}{|c|}{ living room } \\
\hline floor & $0^{\circ}$ & $45^{\circ}$ & $90^{\circ}$ & $135^{\circ}$ & $180^{\circ}$ & $225^{\circ}$ & $270^{\circ}$ & $315^{\circ}$ \\
\hline 1 & -0.158 & -0.137 & -0.093 & -0.016 & 0.111 & 0.087 & 0.026 & -0.105 \\
\hline 2 & -0.157 & -0.138 & -0.093 & -0.015 & 0.109 & 0.072 & 0.025 & -0.106 \\
\hline 3 & -0.160 & -0.140 & -0.093 & -0.021 & 0.103 & 0.056 & 0.024 & -0.109 \\
\hline 4 & -0.160 & -0.141 & -0.092 & -0.021 & 0.097 & 0.041 & 0.022 & -0.112 \\
\hline 5 & -0.160 & -0.143 & -0.092 & -0.022 & 0.086 & 0.034 & 0.020 & -0.115 \\
\hline 6 & -0.158 & -0.146 & -0.090 & -0.027 & 0.075 & 0.031 & 0.018 & -0.118 \\
\hline 7 & -0.156 & -0.149 & -0.089 & -0.034 & 0.068 & 0.032 & 0.015 & -0.121 \\
\hline 8 & -0.154 & -0.150 & -0.091 & -0.038 & 0.064 & 0.034 & 0.011 & -0.123 \\
\hline 9 & -0.152 & -0.151 & -0.094 & -0.047 & 0.051 & 0.031 & 0.006 & -0.139 \\
\hline 10 & -0.149 & -0.152 & -0.096 & -0.066 & 0.030 & 0.022 & 0.002 & -0.159 \\
\hline 11 & -0.147 & -0.150 & -0.100 & -0.097 & -0.014 & 0.005 & -0.002 & -0.158 \\
\hline 12 & -0.142 & -0.141 & -0.114 & -0.147 & -0.108 & -0.026 & -0.009 & -0.140 \\
\hline \multicolumn{9}{|c|}{ storage room } \\
\hline floor & $0^{\circ}$ & $45^{\circ}$ & $90^{\circ}$ & $135^{\circ}$ & $180^{\circ}$ & $225^{\circ}$ & $270^{\circ}$ & $315^{\circ}$ \\
\hline 1 & -0.160 & -0.135 & -0.093 & 0.000 & 0.112 & 0.087 & 0.026 & -0.107 \\
\hline 2 & -0.160 & -0.136 & -0.093 & 0.004 & 0.110 & 0.073 & 0.025 & -0.108 \\
\hline
\end{tabular}




\begin{tabular}{|c|c|c|c|c|c|c|c|c|}
\hline 3 & -0.162 & -0.138 & -0.093 & 0.006 & 0.105 & 0.056 & 0.024 & -0.110 \\
\hline 4 & -0.161 & -0.140 & -0.091 & 0.008 & 0.098 & 0.041 & 0.022 & -0.113 \\
\hline 5 & -0.160 & -0.142 & -0.090 & 0.006 & 0.087 & 0.031 & 0.020 & -0.116 \\
\hline 6 & -0.159 & -0.145 & -0.088 & 0.004 & 0.077 & 0.029 & 0.017 & -0.119 \\
\hline 7 & -0.157 & -0.148 & -0.086 & -0.007 & 0.070 & 0.030 & 0.015 & -0.122 \\
\hline 8 & -0.154 & -0.149 & -0.088 & -0.018 & 0.062 & 0.033 & 0.011 & -0.132 \\
\hline 9 & -0.152 & -0.150 & -0.091 & -0.029 & 0.054 & 0.038 & 0.007 & -0.145 \\
\hline 10 & -0.149 & -0.151 & -0.091 & -0.047 & 0.033 & 0.027 & 0.002 & -0.157 \\
\hline 11 & -0.146 & -0.147 & -0.091 & -0.076 & -0.021 & 0.012 & -0.003 & -0.167 \\
\hline 12 & -0.142 & -0.140 & -0.095 & -0.125 & -0.103 & -0.024 & -0.012 & -0.143 \\
\hline \multicolumn{9}{|c|}{ bedroom } \\
\hline floor & $0^{\circ}$ & $45^{\circ}$ & $90^{\circ}$ & $135^{\circ}$ & $180^{\circ}$ & $225^{\circ}$ & $270^{\circ}$ & $315^{\circ}$ \\
\hline 1 & -0.107 & -0.133 & -0.124 & -0.127 & -0.185 & -0.040 & -0.015 & -0.064 \\
\hline 2 & -0.107 & -0.133 & -0.126 & -0.131 & -0.184 & -0.041 & -0.016 & -0.064 \\
\hline 3 & -0.108 & -0.134 & -0.126 & -0.135 & -0.185 & -0.040 & -0.016 & -0.063 \\
\hline 4 & -0.108 & -0.134 & -0.126 & -0.139 & -0.187 & -0.040 & -0.016 & -0.063 \\
\hline 5 & -0.108 & -0.135 & -0.127 & -0.141 & -0.190 & -0.039 & -0.016 & -0.064 \\
\hline 6 & -0.108 & -0.137 & -0.128 & -0.143 & -0.192 & -0.037 & -0.017 & -0.066 \\
\hline 7 & -0.108 & -0.140 & -0.129 & -0.145 & -0.191 & -0.037 & -0.017 & -0.071 \\
\hline 8 & -0.109 & -0.145 & -0.129 & -0.148 & -0.189 & -0.036 & -0.018 & -0.076 \\
\hline 9 & -0.111 & -0.152 & -0.130 & -0.152 & -0.187 & -0.037 & -0.019 & -0.080 \\
\hline 10 & -0.114 & -0.150 & -0.133 & -0.160 & -0.185 & -0.038 & -0.020 & -0.081 \\
\hline 11 & -0.119 & -0.141 & -0.133 & -0.171 & -0.183 & -0.040 & -0.020 & -0.077 \\
\hline 12 & -0.130 & -0.127 & -0.135 & -0.189 & -0.181 & -0.043 & -0.020 & -0.077 \\
\hline
\end{tabular}

\subsection{Indoor thermal conditions}

The outcomes of the thermal simulations are presented here first in terms of frequency distribution of the air change rates - expressed in $\mathrm{ACH}$ - achieved in an exemplary room, namely the living room. From the analysis of Figure 11 it is seen how, for most of the time in a year, the number of air change rates achieved is in the range of 1 to $2 \mathrm{ACH}$ for all the scenarios analyzed. When natural ventilation is not employed (SC_0), air change rates are due to leakages only and are always lower than $3 \mathrm{ACH}$ (solid blue line), while under SC_1 (orange line with circle markers) this range is achieved for $48 \%$ of the time. The remaining shows an almost evenly distribution in the range of 3 to $15 \mathrm{ACH}$ (the graph is truncated at $5 \mathrm{ACH}$ for the sake of clearness). Intermediate results are achieved when the opening of the windows is modulated according to outdoor PM2.5 concentrations thresholds set by the Chinese government (SC_2, grey line with rhomboidal markers) and by the WHO (SC_3, yellow line with square markers) respectively. The other rooms present higher air change rate values, usually in the range of 2 to $4 \mathrm{ACH}$ for most of the time and with a peak of around $30 \mathrm{ACH}$ achieved in the bedroom. 


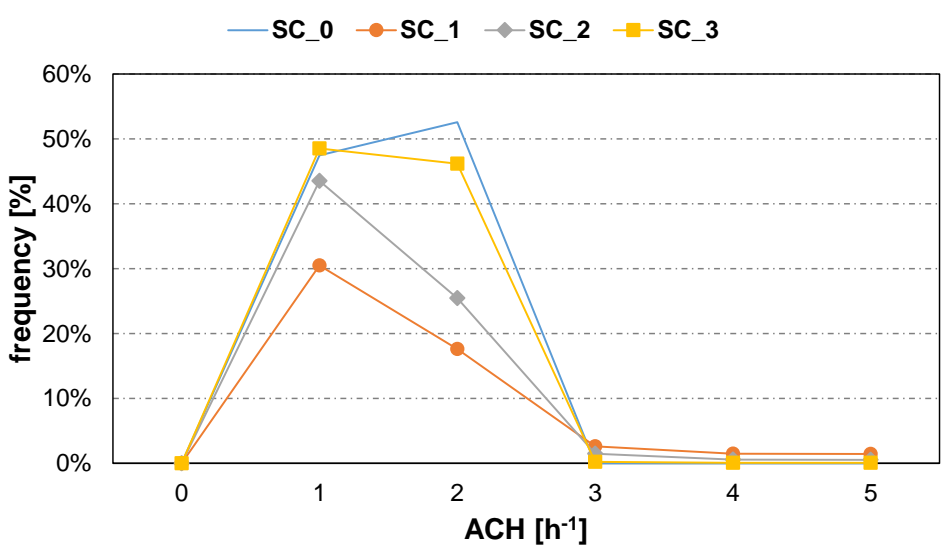

Figure 11. Frequency distribution of the air change rates achieved in the living room according to the different scenarios

In order to compare the behavior of different rooms for the different scenarios, Figure 12 plots the annual average air change rate achievable in each room of the study flat together with the corresponding windows opening time. The toilet is neglected because it is not provided with any opening suitable for natural ventilation purposes.

From Figure 12 it is shown that, if excluding any opening of the windows (SC_0), the average air change rate achieved is due to air infiltrations only from the windows and other leakages from the envelope, and varies from a minimum of $1 \mathrm{ACH}$ in the living room to a maximum of $2.5 \mathrm{ACH}$ in the kitchen. When the windows are opened according to the control logic described in Section 5.1 and irrespective of outdoor pollution concentrations (SC_1), the amount of fresh air that is possible to bring inside is much higher. In fact, by modulating the opening of the windows in order to reach the comfort conditions of Table 4, the annual average air change rate achievable is in the order of $10 \mathrm{ACH}$ in the bedroom and in the storage room, of around $8 \mathrm{ACH}$ in the living room and reaches its maximum in the kitchen with approximately $15 \mathrm{ACH}$. These air change rates can be reached under the actual sliding windows configuration if venting for $50 \%$ of the time the bedroom and the kitchen, and for around $55 \%$ of the time if venting the living room and the storage room (yellow diamond markers, secondary $\mathrm{y}$-axis of Figure 12). 


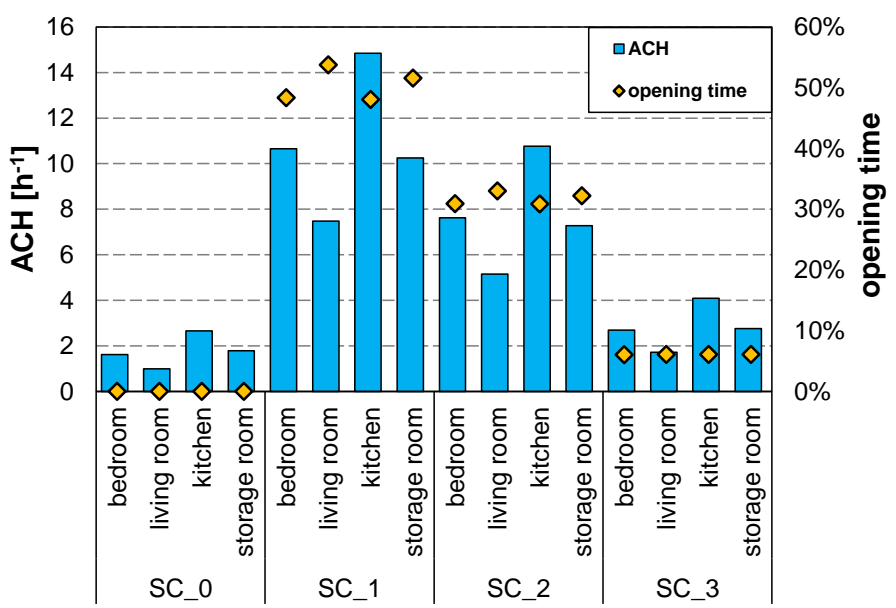

Figure 12. Annual average air change rates and windows opening time for different rooms according to the different scenarios

The resulting amount of comfort hours, expressed as a percentage of the annual hours, is reported in Figure 13, where it is easy to appreciate the improvements achievable when natural ventilation is employed. In fact, the amount of comfort hours experienced in a year rises from around $30 \%$ in the existing configuration where a NV strategy is not deployed (SC_0), to around 50\% (with a peak of $60 \%$ of time for the living room) when NV is used according to the conditions set for SC_1.

However, when taking into account the reductions due to outdoor pollution, the amount of comfort hours drop down to around $45 \%$ if ventilation is not allowed when outdoor PM2.5 concentrations are above the threshold of $35 \mu \mathrm{gm}^{-3}$ (SC_2). Almost no improvements are expected for SC_3 with respect to the base case (SC_0), i.e. when the more stringent threshold of $10 \mu \mathrm{gm}^{-3}$ regulates the opening of the windows, which is in line with an average opening time of just $6 \%$ during transition and summer hours as shown in Figure 12.

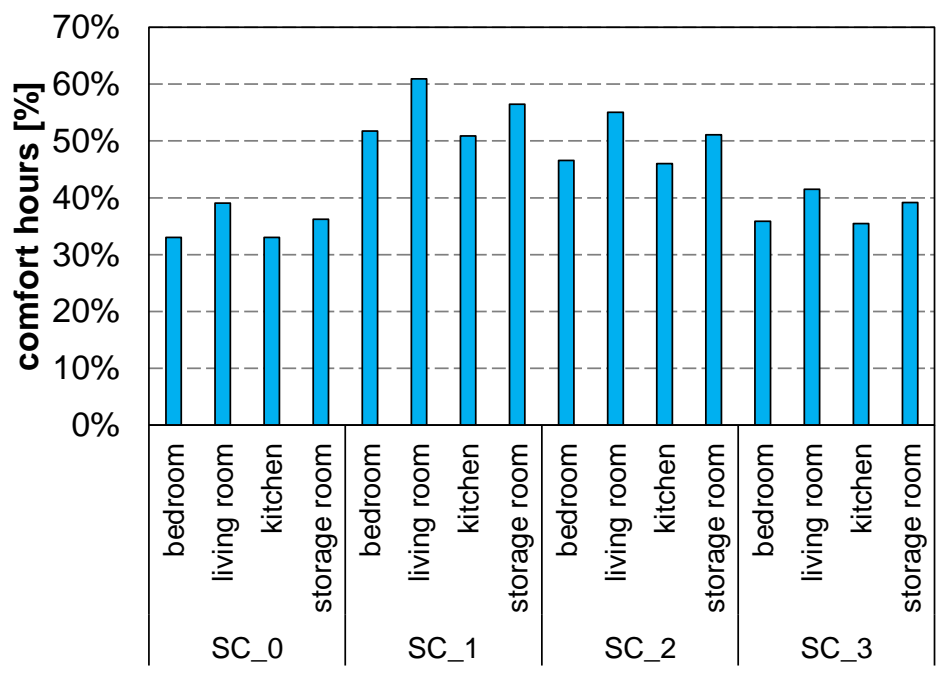




\section{Discussion}

4 The use of natural ventilation as a measure to bring fresh air inside and provide better indoor comfort conditions in dense and polluted environments is a challenging task that designers and building scientists have to face. First, the influence of the urban configuration may be significant, especially when the buildings are surrounded by taller ones. Under such circumstances, the calculation of the coefficients of pressure reported in Section 4.1 showed that reductions can be in the order of three to four times the values achieved by the undisturbed building facades (i.e. those not sheltered from other buildings).

Although these results are not generalizable because they strictly depend on the specific study context, so that more analysis of this kind are encouraged for different urban layouts to draw more robust conclusions, they give a reliable estimate of the role played by the urban context.

Secondly, outdoor pollution should be accounted for when taking decisions on the use of a natural ventilation strategy. This is especially true for developing countries like China, where recorded outdoor pollutant concentrations are usually much higher than the threshold values suggested by the WHO (almost five times higher for the city of Chongqing on a year average basis).

The combined effects of both urban and pollution factors can be appraised if looking at Figure 14. Here the NV potential, given as the number of hours when windows are open according to SC_1 (no consideration for outdoor pollution), SC_2 (outdoor PM2.5 concentrations are lower than the Chinese threshold) and SC_3 (PM2.5 concentrations are lower than the WHO threshold), is plotted against the percent hours reductions of $\mathrm{SC}_{-} 2$ and $\mathrm{SC}_{-} 3$ with respect to $\mathrm{SC}_{-} 1$. The room considered is the bedroom, although no significant changes are recorded if considering other rooms in the flat.

It is easy to notice a tremendous reduction when passing from SC_1 (windows open for 4234 hours in a year) to SC_2 (opening time of 2707 hours, 36\% reduction) and SC_3 (just 529 hours, equal to $88 \%$ reduction) in order.

This has obvious implications in terms of thermal comfort as discussed in Section 4.3, with an increase of the number of comfort hours with respect to the base case depicted by SC_0 of 18\%, 13\% and $2 \%$ only for SC_1, SC_2 and SC_3 respectively (see Figure 14). 


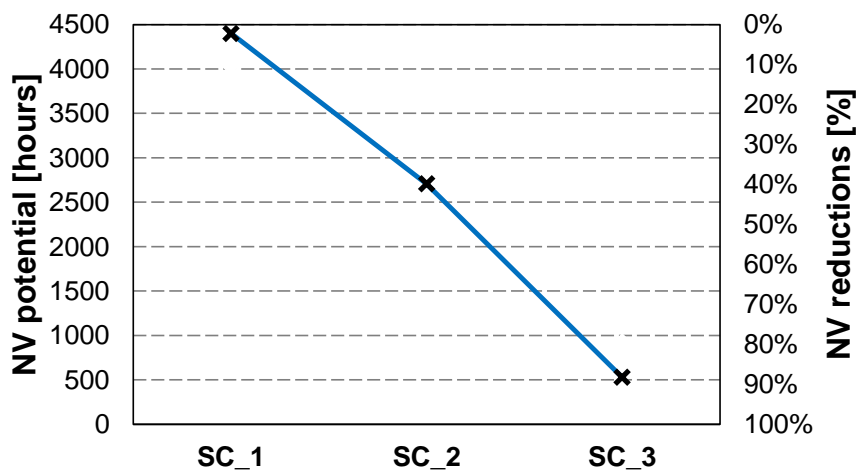

Figure 14. Natural ventilation potential and reductions according to the different scenarios

Finally, it is worth to mention some of the limitations of the approach employed, and how they may influence the outcomes discussed so far. Indeed, this research does not aim to provide designers with optimal design configurations in terms of windows, building orientation and envelope characteristics to maximize the number of air change rates and comfort hours achievable. The scope is rather to give an order of magnitude of the reductions in the NV potential in densely-built up and highly polluted environments. In this sense, windows opening behavior is not considered as well.

Further, our modelling approach did not report on indoor PM2.5 concentrations because in the absence of indoor sources (as typically happens in residential and public buildings) and of deposition effects onto indoor surfaces that would rather reduce indoor values as reported in [30], they keep the same as outdoors and thus there is no interest in reporting them.

\section{Conclusions}

This paper presents a holistic approach combining thermal and CFD simulations to assess the potential of natural ventilation for residential buildings located in dense and highly polluted environments.

The approach has been demonstrated for a typical apartment located in the Yuzhong district of Chongqing city (China) accounting for both the urban sheltering effects and outdoor pollution levels (PM2.5 particles concentrations namely) when estimating indoor thermal conditions. First, the coefficients of pressure at every façade of the study area have been calculated with CFD simulations in ANSYS according to different wind directions. Then, together with the hourly values of PM2.5 concentrations and of the main climate variables recorded from local weather stations, this information is passed to the EnergyPlus software to run detailed thermal simulations for a model validated with experimental measurements.

Scenario analysis revealed that urban sheltering effects in the study area can reduce the coefficients 
of pressure, which linearly relate to wind-driven natural ventilation potential, up to a quarter of the values achieved by undisturbed facades (i.e. those not sheltered from the surroundings).

The annual average amount of air change rates achievable when naturally ventilating the case study building irrespective of outdoor PM2.5 concentrations ( $\left.\mathrm{SC}_{-} 1\right)$ thus ranges from 8 to $15 \mathrm{ACH}$, according to the windows orientation and height from the ground. The corresponding values expected when closing the windows if hourly outdoor PM2.5 concentrations are higher than the annual

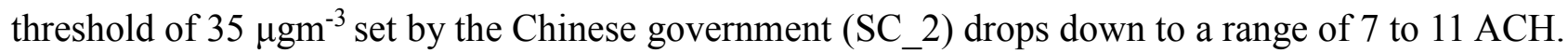
If the more stringent WHO threshold of $10 \mu \mathrm{gm}^{-3}$ is used instead (SC_3), the values achieved are just slightly higher than those of the base case scenario, where natural ventilation is not employed and the air change rates are due to leakages from the envelope only (found on average in the range of 1 to 2.5 $\mathrm{ACH})$.

The resulting number of annual comfort hours, computed according to the adaptive comfort theory and considering local people thermal preferences, can be increased with respect to the base of around $18 \%, 13 \%$ and $2 \%$ only for $\mathrm{SC} \_1, \mathrm{SC} \_2$ and $\mathrm{SC} \_3$ respectively comparing to the case with no NV applied.

It is thus found a tremendous reduction of the natural ventilation potential - expressed in terms of windows opening hours - with outdoor pollution threshold values. Indeed, the number of hours during which the windows are open under SC_1 amounts to 4234 hours, while under SC_2 and SC_3 the figures are of 2707 hours (36\% reduction) and 529 hours only ( $88 \%$ reduction) respectively.

These findings are intended to help designers and building scientists understand the constraints to the application of natural ventilation techniques in dense and polluted environments, and to not overestimate the benefits achievable in terms of fresh air provision and thermal comfort conditions.

\section{Acknowledgments}

The research work is based on the UK-China collaborative research project 'Low carbon climateresponsive Heating and Cooling of Cities (LoHCool)' supported by the National Natural Science Foundation of China [NSFC Grant No. 51561135002] and the UK Engineering and Physical Sciences Research Council [EPSRC Grant No. EP/N009797/1]. The research is associated with the China National Key R\&D Programme 'Solutions to Heating and Cooling of Buildings in the Yangtze River Region' [Grant No: 2016YFC0700301]. Mr. Jie Xiong would like to thank the China Scholarship Council for its financial support as a sponsored researcher at the University of Reading [Grant No: 201706050009].

\section{Nomenclature}




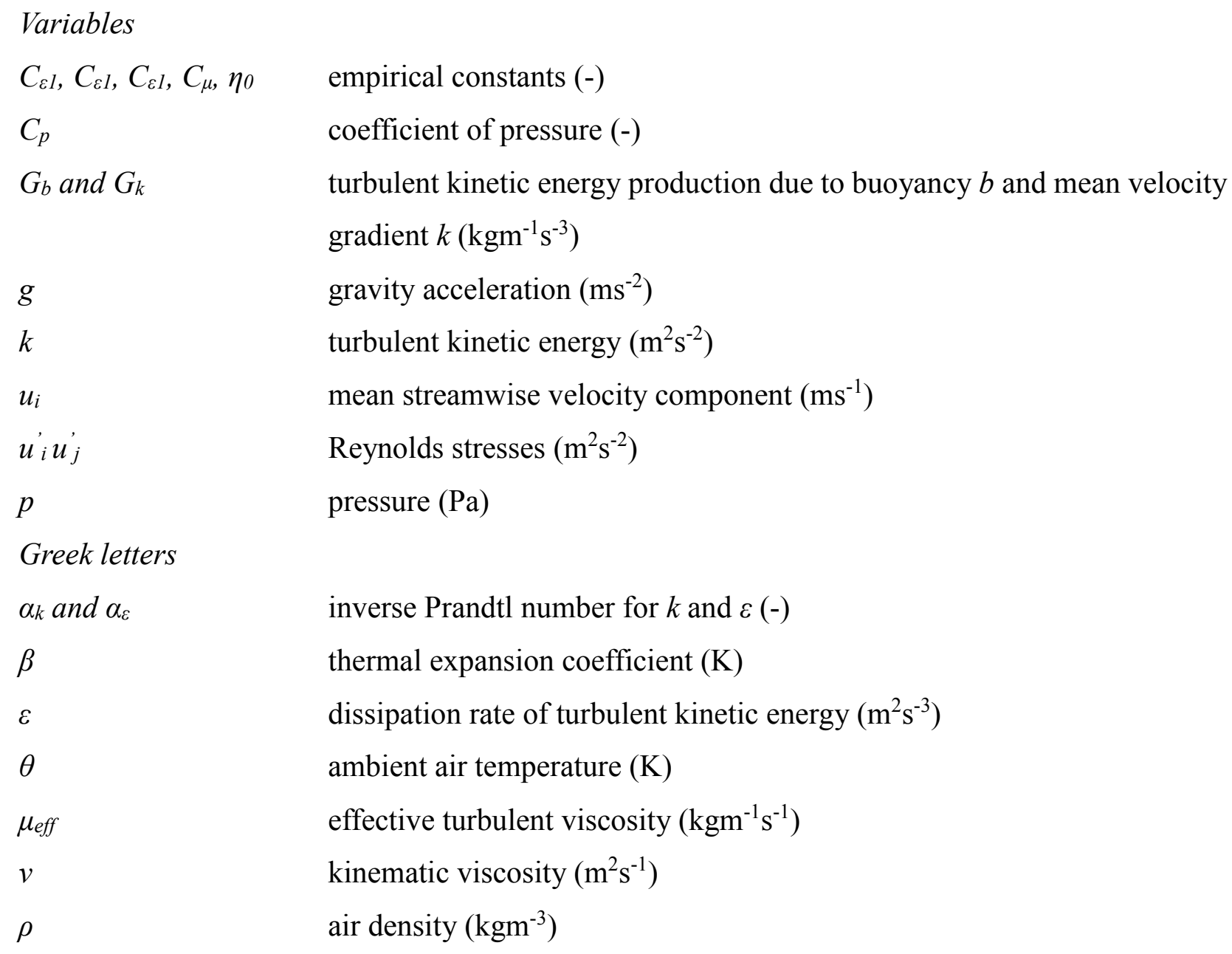

\section{References}

3 [1] U. Berardi, A cross-country comparison of the building energy consumptions and their 4 trends, Resour. Conserv. Recycl. 123 (2017) 230-241. doi:10.1016/j.resconrec.2016.03.014.

5 [2] B. Li, R. Yao, Urbanisation and its impact on building energy consumption and efficiency 6 in China, Renew. Energy. 34 (2009) 1994-1998. doi:10.1016/j.renene.2009.02.015.

7 [3] NRDC (National Development and Reform Commission of Peoples' Republic of China), 8 Enhanced Actions on Climate Change: China's Intended Nationally Determined Contribution, 9 Beijing, 2015..

10 [4] M.A. McNeil, W. Feng, S. de la Rue du Can, N.Z. Khanna, J. Ke, N. Zhou, Energy 11 efficiency outlook in China's urban buildings sector through 2030, Energy Policy. 97 (2016) 532539. doi:10.1016/j.enpol.2016.07.033.

13 [5] CPC Central Committee and State Council, 'Healthy China 2030' Plan, 2016.

[6] Tsinghua University Building Energy Research Center, 2016 Annual Report on China Building Energy Efficiency, Energy Efficiency, China Architecture \& Building Press, Beijing, 2016. 
[8] Z. Wang, R. de Dear, B. Lin, Y. Zhu, Q. Ouyang, Rational selection of heating temperature set points for China's hot summer - Cold winter climatic region, Build. Environ. 93 (2015) 63-70. doi:10.1016/j.buildenv.2015.07.008.

[9] B. Li, C. Du, R. Yao, W. Yu, V. Costanzo, Indoor thermal environments in Chinese residential buildings responding to the diversity of climates, Appl. Therm. Eng. 129 (2017) 693-708. doi:10.1016/j.applthermaleng.2017.10.072.

[10] A. Leaman, B. Bordass, Are users more tolerant of 'green' buildings?, Build. Res. Inf. 35 (2007) 662-673. doi:10.1080/09613210701529518.

[11] H. Liu, Y. Wu, B. Li, Y. Cheng, R. Yao, Seasonal variation of thermal sensations in residential buildings in the Hot Summer and Cold Winter zone of China, Energy Build. 140 (2017) 9-18. doi:10.1016/j.enbuild.2017.01.066.

[12] K.A. Al-Sallal, L. Al-Rais, Outdoor airflow analysis and potential for passive cooling in the traditional urban context of Dubai, Renew. Energy. 36 (2011) 2494-2501. doi:10.1016/j.renene.2011.01.035.

[13] R. Ramponi, B. Blocken, L.B. de Coo, W.D. Janssen, CFD simulation of outdoor ventilation of generic urban configurations with different urban densities and equal and unequal street widths, Build. Environ. 92 (2015) 152-166. doi:10.1016/j.buildenv.2015.04.018.

[14] P. Nie, J. Zhou, B. Tong, Q. Zhang, G. Zhang, Numerical Study on the Effect of Natural Ventilation and Optimal Orientation of Residential Buildings in Changsha, China, Procedia Eng. 121 (2015) 1230-1237. doi:10.1016/j.proeng.2015.09.150.

[15] X. Fu, X. Qian, L. Wang, Energy efficiency for airtightness and exterior wall insulation of passive houses in hot summer and cold winter zone of China, Sustain. 9 (2017). doi:10.3390/su9071097.

[16] R. Yao, V. Costanzo, X. Li, Q. Zhang, B. Li, The effect of passive measures on thermal comfort and energy conservation. A case study of the Hot Summer and Cold Winter climate in the Yangtze River region, J. Build. Eng. 15 (2017) 298-310. doi:10.1016/j.jobe.2017.11.012.

[17] X. Wang, H. Altan, J. Kang, Parametric study on the performance of green residential buildings in China, Front. Archit. Res. 4 (2015) 56-67. doi:10.1016/j.foar.2014.06.007.

[18] J. Wang, B. Zhao, S. Wang, F. Yang, J. Xing, L. Morawska, A. Ding, M. Kulmala, V.M. Kerminen, J. Kujansuu, Z. Wang, D. Ding, X. Zhang, H. Wang, M. Tian, T. Petäjä, J. Jiang, J. Hao, Particulate matter pollution over China and the effects of control policies, Sci. Total Environ. 584585 (2017) 426-447. doi:10.1016/j.scitotenv.2017.01.027.

[19] Z. Cheng, L. Luo, S. Wang, Y. Wang, S. Sharma, H. Shimadera, X. Wang, M. Bressi, R.M. de Miranda, J. Jiang, W. Zhou, O. Fajardo, N. Yan, J. Hao, Status and characteristics of ambient PM2.5pollution in global megacities, Environ. Int. 89-90 (2016) 212-221. doi:10.1016/j.envint.2016.02.003.

[20] C.K. Chan, X. Yao, Air pollution in mega cities in China, Atmos. Environ. 42 (2008) 1-42. doi:10.1016/j.atmosenv.2007.09.003.

[21] K. Matus, K.M. Nam, N.E. Selin, L.N. Lamsal, J.M. Reilly, S. Paltsev, Health damages from air pollution in China, Glob. Environ. Chang. 22 (2012) 55-66. 
doi:10.1016/j.gloenvcha.2011.08.006.

[22] Q. Zhang, M. Qiu, K. Lai, N. Zhong, Cough and environmental air pollution in China, Pulm. Pharmacol. Ther. 35 (2015) 132-136. doi:10.1016/j.pupt.2015.10.003.

[23] Y. Toparlar, B. Blocken, B. Maiheu, G.J.F. van Heijst, A review on the CFD analysis of urban microclimate, Renew. Sustain. Energy Rev. 80 (2016) 1613-1640. doi:10.1016/j.rser.2017.05.248.

[24] V. Costanzo, M. Donn, Thermal and visual comfort assessment of natural ventilated office buildings in Europe and North America, Energy Build. 140 (2017) 210-223. doi:10.1016/j.enbuild.2017.02.003.

[25] R. Ramponi, I. Gaetani, A. Angelotti, Influence of the urban environment on the effectiveness of natural night-ventilation of an office building, Energy Build. 78 (2014) 24-34. doi:10.1016/j.enbuild.2014.04.001.

[26] J.O.P. Cheung, C.H. Liu, CFD simulations of natural ventilation behaviour in high-rise buildings in regular and staggered arrangements at various spacings, Energy Build. 43 (2011) 11491158. doi:10.1016/j.enbuild.2010.11.024.

[27] X. Du, R. Bokel, A. van den Dobbelsteen, Building microclimate and summer thermal comfort in free-running buildings with diverse spaces: A Chinese vernacular house case, Build. Environ. 82 (2014) 215-227. doi:10.1016/j.buildenv.2014.08.022.

[28] K.A. Al-Sallal, L. Al-Rais, Outdoor airflow analysis and potential for passive cooling in the modern urban context of Dubai, Renew. Energy. 38 (2012) 40-49. doi:10.1016/j.renene.2011.06.046.

[29] W. Yang, N.H. Wong, Y. Lin, Thermal Comfort in High-rise Urban Environments in Singapore, Procedia Eng. 121 (2015) 2125-2131. doi:10.1016/j.proeng.2015.09.083.

[30] J.S. Park, N.Y. Jee, J.W. Jeong, Effects of types of ventilation system on indoor particle concentrations in residential buildings, Indoor Air. 24 (2014) 629-638. doi:10.1111/ina.12117.

[31] Z. Tong, Y. Chen, A. Malkawi, G. Adamkiewicz, J.D. Spengler, Quantifying the impact of traffic-related air pollution on the indoor air quality of a naturally ventilated building, Environ. Int. 89-90 (2016) 138-146. doi:10.1016/j.envint.2016.01.016.

[32] F. Yang, Y. Kang, Y. Gao, K. Zhong, Numerical simulations of the effect of outdoor pollutants on indoor air quality of buildings next to a street canyon, Build. Environ. 87 (2015) 10-22. doi:10.1016/j.buildenv.2015.01.008.

[33] Z. Tong, Y. Chen, A. Malkawi, Z. Liu, R.B. Freeman, Energy saving potential of natural ventilation in China: The impact of ambient air pollution, Appl. Energy. 179 (2016) 660-668. doi:10.1016/j.apenergy.2016.07.019.

[34] GB 3095. China national ambient air quality standards. Ministry of Environmental Protection of the People's Republic of China; 2012.

[35] N.R. Martins, G. Carrilho da Graça, Simulation of the effect of fine particle pollution on the potential for natural ventilation of non-domestic buildings in European cities, Build. Environ. 115 (2017) 236-250. doi:10.1016/j.buildenv.2017.01.030.

[36] N.R. Martins, G. Carrilho da Graça, Impact of outdoor PM2.5 on natural ventilation 
usability in California's nondomestic buildings, Appl. Energy. 189 (2017) 711-724. doi:10.1016/j.apenergy.2016.12.103.

[37] N.R. Martins, G. Carrilho da Graça, Effects of airborne fine particle pollution on the usability of natural ventilation in office buildings in three megacities in Asia, Renew. Energy. 117 (2018) 357-373. doi:10.1016/j.renene.2017.10.089.

[38] World Health Organization, WHO Air Quality Guidelines Global Update 2005, Report on a Working Group Meeting, WHO Regional Office for Europe, Bonn, Germany, 18-20 October 2005, ISBN 92-890-2192-6

[39] General Administration of Quality Supervision, Inspection and Quarantine, Ministry of Environmental Protection of China. GB 3095-2012 Ambient air quality standards. Beijing: China Environmental Science Press, 2012.

[40] ANSYS, Inc. and ANSYS Europe, Ltd., ANSYS Fluent Theory Guide, Canonsburg: SAS IP, Inc., 2017.

[41] G.M. Stavrakakis, E. Tzanaki, V.I. Genetzaki, A computational methodology for effective bioclimatic-design applications in the urban environment, Sustain. Cities \& Soc. 4(1) (2012) 41-57

[42] R.A. Memon, D.Y.C. Leung, C.H. Liu, Effects of building aspect ratio and wind speed on air temperatures in urban-like street canyons, Build. Environ. 45 (2010) 176-188. doi:10.1016/j.buildenv.2009.05.015

[43] R.A. Memon, D.Y.C. Leung, On the heating environment in street canyon, Environ. Fluid Mech. 11 (2011) 465-480. doi:10.1007/s10652-010-9202-z.

[44] G. Evola, V. Popov, Computational analysis of wind driven natural ventilation in buildings, Energy Build 38 (2006) 491-501.

[45] G.M. Stavrakakis, M.K. Koukou, M.G. Vrachopoulos, Natural cross-ventilation in buildings: building-scale experiments, numerical simulation and thermal comfort evaluationm Energy Build 40 (2008) 1666-1681.

[46] C.F. Gao, W.L. Lee, Evaluating the influence of openings configuration on natural ventilation performance of residential units in Hong Kong, Build Environ 46 (2011) 961-969.

[47] T.N. Anh, S. Reiter, The effect of ceiling configurations on indoor air motion and ventilation flow rates, Build Environ 46 (2011) 1211-1222.

[48] Z.T. Ai, C.M. Mak, J.L. Niu, Numerical investigation of wind-induced airflow and inter-unit dispersion characteristics in multistory residential buildings, Indoor Air 23 (2013) 417-429.

[49] Z.T. Ai, C.M. Mak, Determination of single-sided ventilation rates in multistory buildings: evaluation of methods, Energy Build 69 (2014) 292-300.

[50] Load code for the design of building structure.GB50009-2001

[51] US Department of Energy, EnergyPlus Version, 20148.4 (accessed January 2018) http://apps1.eere.energy.gov/buildings/energyplus

[52] D. Coakley, P. Raftery, P. Molloy, Calibration of whole building energy simulation models: detailed case study of a naturally ventilated building using hourly measured data, Proceedings of BSO 2012 Conference, Loughborough (UK), 57-64. 
1 [53] Z. Zhai, M.H. Johnson, M. Krarti, Assessment of natural and hybrid ventilation models in 2 whole-building energy simulations, Energy Build. 43 (2011) 2251-2261. 3 doi:10.1016/j.enbuild.2011.06.026.

4 [54] R.J. De Dear, G.S. Brager, Thermal comfort in naturally ventilated buildings: Revisions to 5 ASHRAE Standard 55, Energy Build. 34 (2002) 549-561. doi:10.1016/S0378-7788(02)00005-1.

6 [55] R. Yao, B. Li, J. Liu, A theoretical adaptive model of thermal comfort - Adaptive Predicted 7 Mean Vote (aPMV), Build. Environ. 44 (2009) 2089-2096. doi:10.1016/j.buildenv.2009.02.014.

8 [56] Fanger PO. Thermal comfort. Copenhagen, Denmark: Danish Technical Press; 1970

9 [57] GB 50736. Design code for heating ventilation and air conditioning of civil buildings (in 10 Chinese). Beijing: China architecture and building press, 2012

11 [58] MOHURD, Design Standard for Energy Efficiency of Residential Buildings in Hot 12 Summer and Cold Winter Zone, JGJ 134-2001 (in Chinese), 2001

[59] Y. Wei, W. Di, B. Li, Multi-objective design method of improving the indoor thermal environment with low energy consumption in residential building, Journal of Civil, Architectural and Environmental Engineering 38(4) (2016) 13-19.

[60] W. Na, Analysis on the advantages and disadvantages of architectural design of large residential area, Private science and technology 9 (2010) 236-236. 